\title{
The hybrid block iterative algorithm for solving the system of equilibrium problems and variational inequality problems
}

\author{
Siwaporn Saewan ${ }^{1}$ and Poom Kumam ${ }^{1 *}$
}

\begin{abstract}
In this paper, we construct the hybrid block iterative algorithm for finding a common element of the set of common fixed points of an infinite family of closed and uniformly quasi - $\phi$ - asymptotically nonexpansive mappings, the set of the solutions of the variational inequality for an $\alpha$-inverse-strongly monotone operator, and the set of solutions of a system of equilibrium problems. Moreover, we obtain a strong convergence theorem for the sequence generated by this process in the framework Banach spaces. The results presented in this paper improve and generalize some well-known results in the literature.
\end{abstract}

Keywords: Hybrid block iterative algorithm, Inverse-strongly monotone operator, Variational inequality, A system of equilibrium problem, Uniformly quasi- $\phi$-asymptotically nonexpansive mapping

2000 Mathematics Subject Classification: 47H05,47H09, 47H10

\section{Introduction}

In the theory of variational inequalities, variational inclusions, and equilibrium problems, the development of an efficient and implementable iterative algorithm is interesting and important. Equilibrium theory represents an important area of mathematical sciences such as optimization, operations research, game theory, financial mathematics and mechanics. Equilibrium problems include variational inequalities, optimization problems, Nash equilibria problems, saddle point problems, fixed point problems, and complementarity problems as special cases.

Let $C$ be a nonempty closed convex subset of a real Banach space $E$ with $\|\cdot\|$ and $E^{*}$ the dual space of $E$ and $A$ : $C \rightarrow E^{*}$ be an operator. The classical variational inequality problem for an operator $\mathrm{A}$ is to find $x^{*} \in C$ such that

$$
\left\langle A x^{*}, y-x^{*}\right\rangle \geq 0, \quad \forall y \in C .
$$

${ }^{*}$ Correspondence: poom.kum@kmutt.ac.th

${ }^{1}$ Department of Mathematics, Faculty of Science, King Mongkut's University of Technology Thonburi (KMUTT), Bangmod, Bangkok 10140, Thailand
The set of solution of (1.1) is denoted by $V I(A, C)$. Recall that let $A: C \rightarrow E^{*}$ be a mapping. Then $\mathrm{A}$ is called

(i) monotone if

$$
\langle A x-A y, x-y\rangle \geq 0, \quad \forall x, y \in C,
$$

(ii) $\alpha$-inverse-strongly monotone if there exists a constant $\alpha>0$ such that

$$
\langle A x-A y, x-y\rangle \geq \alpha\|A x-A y\|^{2}, \quad \forall x, y \in C .
$$

Such a problem is connected with the convex minimization problem, the complementary problem, the problem of finding a point $x^{*} \in E$ satisfying $A x^{*}=0$.

Let $\left\{f_{i}\right\}_{i \in \Gamma}: C \times C \rightarrow \mathbb{R}$ be a bifunction, $\left\{\varphi_{i}\right\}_{i \in \Gamma}: C \rightarrow \mathbb{R}$ be a real-valued function, where $\Gamma$ is an arbitrary index set. The system of equilibrium problems, is to find $x \in C$ such that

$$
f_{i}(x, y) \geq 0, \quad i \in \Gamma, \quad \forall y \in C .
$$

The set of solution of (1.2) is denoted by SEP. If $\Gamma$ is a singleton, then problem (1.2) reduces to the equilibrium problem, is to find $x \in C$ such that

$$
f(x, y) \geq 0, \quad \forall y \in C .
$$

\section{照 Springer}


The set of solution of (1.3) is denoted by $E P(f)$. The above formulation (1.3) was shown in (Blum and Oettli 1994) to cover monotone inclusion problems, saddle point problems, minimization problems, optimization problems, variational inequality problems, vector equilibrium problems, Nash equilibria in noncooperative games. In addition, there are several other problems, for example, the complementarity problem, fixed point problem and optimization problem, which can also be written in the form of an $E P(f)$. In other words, the $E P(f)$ is an unifying model for several problems arising in physics, engineering, science, optimization, economics, etc. In the last two decades, many papers have appeared in the literature on the existence of solutions of $E P(f)$; see, for example (Blum and Oettli 1994; Combettes and Hirstoaga 2005) and references therein. Some solution methods have been proposed to solve the $E P(f)$; see, for example, (Blum and Oettli 1994; Combettes and Hirstoaga 2005; Jaiboon and Kumam 2010; Katchang and Kumam 2010; Kumam 2009; Moudafi 2003; Qin et al. 2009a,2009b,2009c; Saewan and Kumam 2010b,2011a,2011b,2011c,2011d,2011e,2011f, 2011g,2012b; Zegeye et al. 2010) and references therein.

For each $p>1$, the generalized duality mapping $J_{p}$ : $E \rightarrow 2^{E^{*}}$ is defined by

$$
J_{p}(x)=\left\{x^{*} \in E^{*}:\left\langle x, x^{*}\right\rangle=\|x\|^{p},\left\|x^{*}\right\|=\|x\|^{p-1}\right\}
$$

for all $x \in E$. In particular, $J=J_{2}$ is called the normalized duality mapping. If $E$ is a Hilbert space, then $J=I$, where $I$ is the identity mapping. Consider the functional defined by

$$
\phi(x, y)=\|x\|^{2}-2\langle x, J y\rangle+\|y\|^{2}, \quad \forall x, y \in E .
$$

As well know that if $C$ is a nonempty closed convex subset of a Hilbert space $H$ and $P_{C}: H \rightarrow C$ is the metric projection of $H$ onto $C$, then $P_{C}$ is nonexpansive. This fact actually characterizes Hilbert spaces and consequently, it is not available in more general Banach spaces. It is obvious from the definition of function $\phi$ that

$$
(\|x\|-\|y\|)^{2} \leq \phi(x, y) \leq(\|x\|+\|y\|)^{2}, \quad \forall x, y \in E .
$$

If $E$ is a Hilbert space, then $\phi(x, y)=\|x-y\|^{2}$, for all $x, y \in E$. On the author hand, the generalized projection (Alber 1996) $\Pi_{C}: E \rightarrow C$ is a map that assigns to an arbitrary point $x \in E$ the minimum point of the functional $\phi(x, y)$, that is, $\Pi_{C} x=\bar{x}$, where $\bar{x}$ is the solution to the minimization problem

$$
\phi(\bar{x}, x)=\inf _{y \in C} \phi(y, x),
$$

existence and uniqueness of the operator $\Pi_{C}$ follows from the properties of the functional $\phi(x, y)$ and strict monotonicity of the mapping $J$ (see, for example, Alber 1996;
Alber and Reich 1994; Cioranescu 1990; Kamimura and Takahashi 2002; Takahashi 2000).

Remark 1.1. If $E$ is a reflexive, strictly convex and smooth Banach space, then for $x, y \in E, \phi(x, y)=0$ if and only if $x=y$. It is sufficient to show that if $\phi(x, y)=0$ then $x=y$. From (1.4), we have $\|x\|=\|y\|$. This implies that $\langle x, J y\rangle=\|x\|^{2}=\|J y\|^{2}$. From the definition of $J$, one has $J x=J y$. Therefore, we have $x=y$; see (Cioranescu 1990; Takahashi 2000) for more details.

Let $C$ be a closed convex subset of $E$, a mapping $T: C \rightarrow$ $C$ is said to be L-Lipschitz continuous if $\|T x-T y\| \leq L \| x-$ $y \|, \forall x, y \in C$ and a mapping $T$ is said to be nonexpansive if $\|T x-T y\| \leq\|x-y\|, \forall x, y \in C$. A point $x \in C$ is a fixed point of $T$ provided $T x=x$. Denote by $F(T)$ the set of fixed points of $T$; that is, $F(T)=\{x \in C: T x=x\}$. Recall that a point $p$ in $C$ is said to be an asymptotic fixed point of $T$ (Reich 1996) if $C$ contains a sequence $\left\{x_{n}\right\}$ which converges weakly to $p$ such that $\lim _{n \rightarrow \infty}\left\|x_{n}-T x_{n}\right\|=0$. The set of asymptotic fixed points of $T$ will be denoted by $\widetilde{F(T)}$.

A mapping $T$ from $C$ into itself is said to be relatively nonexpansive (Nilsrakoo and Saejung 2008; Su et al. 2008; Zegeye and Shahzad 2009) if $\widetilde{F(T)}=F(T)$ and $\phi(p, T x) \leq$ $\phi(p, x)$ for all $x \in C$ and $p \in F(T)$. The asymptotic behavior of a relatively nonexpansive mapping was studied in (Butnariu et al. 2001, 2003; Censor and Reich 1996). $T$ is said to be $\phi$-nonexpansive, if $\phi(T x, T y) \leq \phi(x, y)$ for $x, y \in C . T$ is said to be relatively quasi-nonexpansive if $F(T) \neq \emptyset$ and $\phi(p, T x) \leq \phi(p, x)$ for all $x \in C$ and $p \in$ $F(T) . T$ is said to be quasi- $\phi$-asymptotically nonexpansive if $F(T) \neq \emptyset$ and there exists a real sequence $\left\{k_{n}\right\} \subset[1, \infty)$ with $k_{n} \rightarrow 1$ such that $\phi\left(p, T^{n} x\right) \leq k_{n} \phi(p, x)$ for all $n \geq 1$ $x \in C$ and $p \in F(T)$.

We note that the class of relatively quasi-nonexpansive mappings is more general than the class of relatively nonexpansive mappings (Butnariu et al. 2001, 2003; Censor and Reich 1996; Matsushita and Takahashi 2005; Saewan et al. 2010) which requires the strong restriction: $F(T)=$ $\widetilde{F(T)}$. A mapping $T$ is said to be closed if for any sequence $\left\{x_{n}\right\} \subset C$ with $x_{n} \rightarrow x$ and $T x_{n} \rightarrow y$, then $T x=y$. It is easy to know that each relatively nonexpansive mapping is closed.

Definition 1.2. (Chang et al. 2010 (1) Let $\left\{T_{i}\right\}_{i=1}^{\infty}: C \rightarrow C$ be a sequence of mapping. $\left\{T_{i}\right\}_{i=1}^{\infty}$ is said to be a family of uniformly quasi- $\phi$-asymptotically nonexpansive mappings, if $\cap_{i=1}^{\infty} F\left(T_{i}\right) \neq \emptyset$, and there exists a sequence $\left\{k_{n}\right\} \subset$ $[1, \infty)$ with $k_{n} \rightarrow 1$ such that for each $i \geq 1$

$$
\phi\left(p, T_{i}^{n} x\right) \leq k_{n} \phi(p, x), \forall p \in \cap_{i=1}^{\infty} F\left(T_{i}\right), x \in C, \forall n \geq 1 .
$$


(2) A mapping $T: C \rightarrow C$ is said to be uniformly $L$ Lipschitz continuous, if there exists a constant $L>0$ such that

$$
\left\|T^{n} x-T^{n} y\right\| \leq L\|x-y\|, \quad \forall x, y \in C .
$$

Remark 1.3. It is easy to see that an $\alpha$-inverse-strongly monotone is monotone and $\frac{1}{\alpha}$-Lipschitz continuous.

In 2004, Matsushita and Takahashi (2004) introduced the following iteration: a sequence $\left\{x_{n}\right\}$ defined by

$$
x_{n+1}=\Pi_{C} J^{-1}\left(\alpha_{n} J x_{n}+\left(1-\alpha_{n}\right) J T x_{n}\right),
$$

where the initial guess element $x_{0} \in C$ is arbitrary, $\left\{\alpha_{n}\right\}$ is a real sequence in $[0,1], T$ is a relatively nonexpansive mapping and $\Pi_{C}$ denotes the generalized projection from $E$ onto a closed convex subset $C$ of $E$. They proved that the sequence $\left\{x_{n}\right\}$ converges weakly to a fixed point of $T$.

In 2005, Matsushita and Takahashi (2005) proposed the following hybrid iteration method (it is also called the CQ method) with generalized projection for relatively nonexpansive mapping $\mathrm{T}$ in a Banach space $\mathrm{E}$ :

$$
\left\{\begin{array}{l}
x_{0} \in C \text { chosen arbitrarily, } \\
y_{n}=J^{-1}\left(\alpha_{n} J x_{n}+\left(1-\alpha_{n}\right) J T x_{n}\right) \\
C_{n}=\left\{z \in C: \phi\left(z, y_{n}\right) \leq \phi\left(z, x_{n}\right)\right\} \\
Q_{n}=\left\{z \in C:\left\langle x_{n}-z, J x_{0}-J x_{n}\right\rangle \geq 0\right\} \\
x_{n+1}=\Pi_{C_{n} \cap Q_{n}} x_{0} .
\end{array}\right.
$$

They proved that $\left\{x_{n}\right\}$ converges strongly to $\Pi_{F(T)} x_{0}$, where $\Pi_{F(T)}$ is the generalized projection from $C$ onto $F(T)$. In 2008, Iiduka and Takahashi (2008) introduced the following iterative scheme for finding a solution of the variational inequality problem for an inverse-strongly monotone operator $A$ in a 2-uniformly convex and uniformly smooth Banach space $E: x_{1}=x \in C$ and

$$
x_{n+1}=\Pi_{C} J^{-1}\left(J x_{n}-\lambda_{n} A x_{n}\right),
$$

for every $n=1,2,3, \ldots$, where $\Pi_{C}$ is the generalized metric projection from $E$ onto $C, J$ is the duality mapping from $E$ into $E^{*}$ and $\left\{\lambda_{n}\right\}$ is a sequence of positive real numbers. They proved that the sequence $\left\{x_{n}\right\}$ generated by (1.11) converges weakly to some element of $\operatorname{VI}(A, C)$. Takahashi and Zembayashi $(2008,2009)$, studied the problem of finding a common element of the set of fixed points of a nonexpansive mapping and the set of solutions of an equilibrium problem in the framework of Banach spaces.

In 2009, Wattanawitoon and Kumam (2009) using the idea of Takahashi and Zembayashi (2009) extend the notion from relatively nonexpansive mappings or $\phi$-nonexpansive mappings to two relatively quasinonexpansive mappings and also proved some strong convergence theorems to approximate a common fixed point of relatively quasi-nonexpansive mappings and the set of solutions of an equilibrium problen in the framework of Banach spaces. Cholamjiak (2009), proved the following iteration:

$\left\{\begin{array}{l}z_{n}=\Pi_{C} J^{-1}\left(J x_{n}-\lambda_{n} A x_{n}\right), \\ y_{n}=J^{-1}\left(\alpha_{n} J x_{n}+\beta_{n} J T x_{n}+\gamma_{n} J S z_{n}\right), \\ u_{n} \in C \text { such that } f\left(u_{n}, y\right)+\frac{1}{r_{n}}\left\langle y-u_{n}, J u_{n}-J y_{n}\right\rangle \geq 0, \forall y \in C, \\ C_{n+1}=\left\{z \in C_{n}: \phi\left(z, u_{n}\right) \leq \phi\left(z, x_{n}\right),\right. \\ x_{n+1}=\Pi_{C_{n+1}} x_{0},\end{array}\right.$

where $J$ is the duality mapping on $E$. Assume that $\left\{\alpha_{n}\right\}$, $\left\{\beta_{n}\right\}$ and $\left\{\gamma_{n}\right\}$ are sequence in $[0,1]$. Then $\left\{x_{n}\right\}$ converges strongly to $q=\Pi_{F} x_{0}$, where $F:=F(T) \cap F(S) \cap E P(f) \cap$ $V I(A, C)$.

In 2010, Saewan et al. (2010) introduced a new hybrid projection iterative scheme which is difference from the algorithm (1.12) of Cholamjiak in (2009, Theorem 3.1) for two relatively quasi-nonexpansive mappings in a Banach space. Motivated by the results of Takahashi and Zembayashi (2008); Cholamjiak and Suantai (2010) proved the strong convergence theorem by the hybrid iterative scheme for approximation of a common fixed point of countable families of relatively quasinonexpansive mappings in a uniformly convex and uniformly smooth Banach space: $x_{0} \in E, x_{1}=\Pi_{C_{1}} x_{0}, C_{1}=C$

$$
\left\{\begin{array}{l}
y_{n, i}=J^{-1}\left(\alpha_{n} J x_{n}+\left(1-\alpha_{n}\right) J T x_{n},\right) \\
u_{n, i}=T_{r_{m, n}}^{f_{m}} T_{r_{m-1, n}}^{f_{m-1}} \cdots T_{r_{1, n}}^{f_{1}} y_{n, i} \\
C_{n+1}=\left\{z \in C_{n}: \sup _{i>1} \phi\left(z, J u_{n, i}\right) \leq \phi\left(z, J x_{n}\right)\right\} \\
x_{n+1}=\Pi_{C_{n+1} x_{0}}, n \geq 1
\end{array}\right.
$$

Then, they proved that under certain appropriate conditions imposed on $\left\{\alpha_{n}\right\}$, and $\left\{r_{n, i}\right\}$, the sequence $\left\{x_{n}\right\}$ converges strongly to $\Pi_{C_{n+1}} x_{0}$.

We note that the block iterative method is a method which often used by many authors to solve the convex feasibility problem (see, Kohsaka and Takahashi 2007; Kikkawa and Takahashi 2004, etc.). In 2008, Plubtieng and Ungchittrakool (2008) established strong convergence theorems of block iterative methods for a finite family of relatively nonexpansive mappings in a Banach space by using the hybrid method in mathematical programming. Chang et al (2010) proposed the modified block iterative algorithm for solving the convex feasibility problems for an infinite family of closed and uniformly quasi- $\phi$ asymptotically nonexpansive mappings, they obtained the strong convergence theorems in a Banach space. In 2010, Saewan and Kumam (2010a) obtained the result for the set of solutions of the generalized equilibrium problems and the set of common fixed points of an infinite family of closed and uniformly quasi- $\phi$-asymptotically nonexpansive mappings in a uniformly smooth and strictly convex Banach space $E$ with Kadec-Klee property. 
Very recently, Qin, Cho and Kang (2009a) purposed the problem of approximating a common fixed point of two asymptotically quasi- $\phi$-nonexpansive mappings based on hybrid projection methods. Strong convergence theorems are established in a real Banach space. Zegeye et al. (2010) introduced an iterative process which converges strongly to a common element of set of common fixed points of countably infinite family of closed relatively quasinonexpansive mappings, the solution set of the generalized equilibrium problem and the solution set of the variational inequality problem for an $\alpha$-inverse strongly monotone mapping in Banach spaces.

Motivated and inspired by the work of Chang et al. (2010); Qin et al. (2009c); Takahashi and Zembayashi (2009); Wattanawitoon and Kumam (2009); Zegeye (2010); Saewan and Kumam (2010a, 2012a), we introduce a modified hybrid block projection algorithm for finding a common element of the set of the solution of the variational inequality for an $\alpha$-inverse-strongly monotone operator, and the set of solutions of the system of equilibrium problems and the set of common fixed points of an infinite family of closed and uniformly quasi- $\phi$ asymptotically nonexpansive mappings in a 2-uniformly convex and uniformly smooth Banach space. The results presented in this paper improve and generalize some well-known results in the literature.

\section{Preliminaries}

A Banach space $E$ is said to be strictly convex if $\left\|\frac{x+y}{2}\right\|<1$ for all $x, y \in E$ with $\|x\|=\|y\|=1$ and $x \neq y$. Let $U=$ $\{x \in E:\|x\|=1\}$ be the unit sphere of $E$. Then a Banach space $E$ is said to be smooth if the limit

$$
\lim _{t \rightarrow 0} \frac{\|x+t y\|-\|x\|}{t}
$$

exists for each $x, y \in U$. It is also said to be uniformly smooth if the limit is attained uniformly for $x, y \in U$. Let $E$ be a Banach space. The modulus of convexity of $E$ is the function $\delta:[0,2] \rightarrow[0,1]$ defined by

$$
\delta(\varepsilon)=\inf \left\{1-\left\|\frac{x+y}{2}\right\|: x, y \in E,\|x\|=\|y\|=1,\|x-y\| \geq \varepsilon\right\} .
$$

A Banach space $E$ is uniformly convex if and only if $\delta(\varepsilon)>$ 0 for all $\varepsilon \in(0,2]$. Let $p$ be a fixed real number with $p \geq$ 2. A Banach space $E$ is said to be $p$-uniformly convex if there exists a constant $c>0$ such that $\delta(\varepsilon) \geq c \varepsilon^{p}$ for all $\varepsilon \in[0,2]$; see (Ball et al. 1994; Takahashi et al. 2002) for more details. Observe that every $p$-uniformly convex is uniformly convex. It is well known that a Hilbert space is 2-uniformly convex, uniformly smooth. It is also known that if $E$ is uniformly smooth, then $J$ is uniformly normto-norm continuous on each bounded subset of $E$.

Remark 2.1. The following basic properties can be found in Cioranescu (1990). (i) If $E$ is a uniformly smooth Banach space, then $J$ is uniformly continuous on each bounded subset of $E$.

(ii) If $E$ is a reflexive and strictly convex Banach space, then $J^{-1}$ is norm-weak*-continuous.

(iii) If $E$ is a smooth, strictly convex, and reflexive Banach space, then the normalized duality mapping $J: E \rightarrow 2^{E^{*}}$ is single-valued, one-to-one, and onto.

(iv) A Banach space $E$ is uniformly smooth if and only if $E^{*}$ is uniformly convex.

(v) Each uniformly convex Banach space $E$ has the Kadec-Klee property, that is, for any sequence $\left\{x_{n}\right\} \subset E$, if $x_{n} \rightarrow x \in E$ and $\left\|x_{n}\right\| \rightarrow\|x\|$, then $x_{n} \rightarrow x$.

We also need the following lemmas for the proof of our main results.

Lemma 2.2. (Beauzamy (1985); Xu (1991)). If E be a 2uniformly convex Banach space. Then for all $x, y \in E$, we have

$$
\|x-y\| \leq \frac{2}{c^{2}}\|J x-J y\|,
$$

where $J$ is the normalized duality mapping of $E$ and $0<$ $c \leq 1$.

The best constant $\frac{1}{c}$ in Lemma is called the $p$-uniformly convex constant of $E$.

Lemma 2.3. (Beauzamy (1985); Zalinescu (1983)). If E be a p-uniformly convex Banach space and let $p$ be a given real number with $p \geq 2$. Then for all $x, y \in E, j_{x} \in J_{p}(x)$ and $j_{y} \in J_{p}(y)$

$$
\left\langle x-y, j_{x}-j_{y}\right\rangle \geq \frac{c^{p}}{2^{p-2} p}\|x-y\|^{p},
$$

where $J_{p}$ is the generalized duality mapping of $E$ and $\frac{1}{c}$ is the p-uniformly convexity constant of $E$.

Lemma 2.4. (Kamimura and Takahashi (2002)). Let E be a uniformly convex and smooth Banach space and let $\left\{x_{n}\right\}$ and $\left\{y_{n}\right\}$ be two sequences of $E$. If $\phi\left(x_{n}, y_{n}\right) \rightarrow 0$ and either $\left\{x_{n}\right\}$ or $\left\{y_{n}\right\}$ is bounded, then $\left\|x_{n}-y_{n}\right\| \rightarrow 0$.

Lemma 2.5. (Alber (1996)). Let $C$ be a nonempty closed convex subset of a smooth Banach space E and $x \in E$. Then $x_{0}=\Pi_{C} x$ if and only if

$$
\left\langle x_{0}-y, J x-J x_{0}\right\rangle \geq 0, \quad \forall y \in C .
$$

Lemma 2.6. (Alber (1996, Lemma 2.4)). Let E be a reflexive, strictly convex and smooth Banach space, let $C$ be a nonempty closed convex subset of $E$ and let $x \in E$. Then

$$
\phi\left(y, \Pi_{C} x\right)+\phi\left(\Pi_{C} x, x\right) \leq \phi(y, x), \quad \forall y \in C .
$$

Let $E$ be a reflexive, strictly convex, smooth Banach space and $J$ is the duality mapping from $E$ into $E^{*}$. Then $J^{-1}$ is also single value, one-to-one, surjective, and it is 
the duality mapping from $E^{*}$ into $E$. We make use of the following mapping $V$ studied in Alber (1996)

$$
V\left(x, x^{*}\right)=\|x\|^{2}-2\left\langle x, x^{*}\right\rangle+\left\|x^{*}\right\|^{2},
$$

for all $x \in E$ and $x^{*} \in E^{*}$, that is, $V\left(x, x^{*}\right)=\phi\left(x, J^{-1}\left(x^{*}\right)\right)$. Lemma 2.7. (Alber (1996)). Let $E$ be a reflexive, strictly convex smooth Banach space and let $V$ be as in (2.1). Then

$$
V\left(x, x^{*}\right)+2\left\langle J^{-1}\left(x^{*}\right)-x, y^{*}\right\rangle \leq V\left(x, x^{*}+y^{*}\right),
$$

for all $x \in E$ and $x^{*}, y^{*} \in E^{*}$.

Let $A$ be an inverse-strongly monotone mapping of $C$ into $E^{*}$ which is said to be hemicontinuous if for all $x, y \in$ $C$, the mapping $F$ of $[0,1]$ into $E^{*}$, defined by $F(t)=A(t x+$ $(1-t) y)$, is continuous with respect to the weak* topology of $E^{*}$. We define by $N_{C}(v)$ the normal cone for $C$ at a point $v \in C$, that is,

$$
N_{C}(v)=\left\{x^{*} \in E^{*}:\left\langle v-y, x^{*}\right\rangle \geq 0, \forall y \in C\right\} .
$$

Lemma 2.8. (Rockafellar (1970)). Let C be a nonempty, closed convex subset of a Banach space E and $A$ is a monotone, hemicontinuous operator of $C$ into $E^{*}$. Let $B \subset E \times E^{*}$ be an operator defined as follows:

$$
B v=\left\{\begin{array}{l}
\text { Av+ } N_{C}(v), \quad v \in C \\
\emptyset, \text { otherwise. }
\end{array}\right.
$$

Then $B$ is maximal monotone and $B^{-1} 0=V I(A, C)$.

Lemma 2.9. (Chang et al. (2010)). Let $E$ be a uniformly convex Banach space, $r>0$ be a positive number and $B_{r}(0)$ be a closed ball of $E$. Then, for any given sequence $\left\{x_{i}\right\}_{i=1}^{\infty} \subset B_{r}(0)$ and for any given sequence $\left\{\lambda_{i}\right\}_{i=1}^{\infty}$ of positive number with $\sum_{n=1}^{\infty} \lambda_{n}=1$, there exists a continuous, strictly increasing, and convex function $g:[0,2 r) \rightarrow[0, \infty)$ with $g(0)=0$ such that, for any positive integer $i, j$ with $i<j$,

$$
\left\|\sum_{n=1}^{\infty} \lambda_{n} x_{n}\right\|^{2} \leq \sum_{n=1}^{\infty} \lambda_{n}\left\|x_{n}\right\|^{2}-\lambda_{i} \lambda_{j} g\left(\left\|x_{i}-x_{j}\right\|\right) .
$$

Lemma 2.10. (Chang et al. (2010)). Let E be a real uniformly smooth and strictly convex Banach space, and $C$ be a nonempty closed convex subset of E. Let $T: C \rightarrow C$ be a closed and quasi- $\phi$-asymptotically nonexpansive mapping with a sequence $\left\{k_{n}\right\} \subset[1, \infty), k_{n} \rightarrow 1$. Then $F(T)$ is a closed convex subset of $C$.

For solving the equilibrium problem for a bifunction $f$ : $C \times C \rightarrow \mathbb{R}$, let us assume that $f$ satisfies the following conditions:

(A1) $f(x, x)=0$ for all $x \in C$;

(A2) $f$ is monotone, i.e., $f(x, y)+f(y, x) \leq 0$ for all $x, y \in C$;

(A3) for each $x, y, z \in C$,

$$
\lim _{t \downarrow 0} f(t z+(1-t) x, y) \leq f(x, y) ;
$$

(A4) for each $x \in C, y \mapsto f(x, y)$ is convex and lower semi-continuous.

For example, let $A$ be a continuous and monotone operator of $C$ into $E^{*}$ and define

$$
f(x, y)=\langle A x, y-x\rangle, \forall x, y \in C .
$$

Then, $f$ satisfies (A1)-(A4). The following result is in Blum and Oettli 1994.

Lemma 2.11. (Blum and Oettli (1994)). Let C be a closed convex subset of a smooth, strictly convex and reflexive Banach space $E$, let fbe a bifunction from $C \times C$ to $\mathbb{R}$ satisfying (A1)-(A4), and let $r>0$ and $x \in E$. Then, there exists $z \in C$ such that

$$
f(z, y)+\frac{1}{r}\langle y-z, J z-J x\rangle \geq 0, \quad \forall y \in C .
$$

Lemma 2.12. (Takahashi and Zembayashi (2009)). Let $C$ be a closed convex subset of a uniformly smooth, strictly convex and reflexive Banach space $E$ and let $f$ be a bifunction from $C \times C$ to $\mathbb{R}$ satisfying conditions (A1)-(A4). For all $r>0$ and $x \in E$, define a mapping $T_{r}^{f}: E \rightarrow C$ as follows:

$$
T_{r}^{f} x=\left\{z \in C: f(z, y)+\frac{1}{r}\langle y-z, J z-J x\rangle \geq 0, \quad \forall y \in C\right\} .
$$

Then the following hold:

(1) $T_{r}^{f}$ is single-valued;

(2) $T_{r}^{f}$ is a firmly nonexpansive-type mapping (Kohsaka and Takahashi 2008), that is, for all $x, y \in E$,

$$
\left\langle T_{r}^{f} x-T_{r}^{f} y, J T_{r}^{f} x-J T_{r}^{f} y\right\rangle \leq\left\langle T_{r}^{f} x-T_{r}^{f} y, J x-J y\right\rangle ;
$$

(3) $F\left(T_{r}^{f}\right)=E P(f)$;

(4) $E P(f)$ is closed and convex.

Lemma 2.13. (Takahashi and Zembayashi (2009)). Let C be a closed convex subset of a smooth, strictly convex, and reflexive Banach space $E$, let $f$ be a bifunction from $C \times C$ to $\mathbb{R}$ satisfying (A1)-(A4) and let $r>0$. Then, for $x \in E$ and $q \in F\left(T_{r}^{f}\right)$,

$$
\phi\left(q, T_{r}^{f} x\right)+\phi\left(T_{r}^{f} x, x\right) \leq \phi(q, x) .
$$

\section{Strong convergence theorems}

In this section, we prove the new convergence theorems for finding the set of solutions of system of equilibrium problems, the common fixed point set of a family of closed and uniformly quasi- $\phi$-asymptotically nonexpansive mappings, and the solution set of variational inequalities for an $\alpha$-inverse strongly monotone mapping in a 2-uniformly convex and uniformly smooth Banach space.

Theorem 3.1. Let $C$ be a nonempty closed and convex subset of a 2-uniformly convex and uniformly smooth Banach space $E$. For each $j=1,2, \ldots$, m let $f_{j}$ be a bifunction from 
$C \times C$ to $\mathbb{R}$ which satisfies conditions (A1)-(A4). Let $A$ be an $\alpha$-inverse-strongly monotone mapping of $C$ into $E^{*}$ satisfying $\|A y\| \leq\|A y-A u\|, \quad \forall y \in C$ and $u \in V I(A, C) \neq$ $\emptyset$. Let $\left\{S_{i}\right\}_{i=1}^{\infty}: C \rightarrow C$ be an infinite family of closed uniformly $L_{i}$-Lipschitz continuous and uniformly quasi$\phi$-asymptotically nonexpansive mappings with a sequence $\left\{k_{n}\right\} \subset[1, \infty), k_{n} \rightarrow 1$ such that $F:=\left(\cap_{i=1}^{\infty} F\left(S_{i}\right)\right) \cap$ $\left(\cap_{j=1}^{m} E P\left(f_{j}\right)\right)(\cap V I(A, C))$ is a nonempty and bounded subset in C. For an initial point $x_{0} \in E$ with $x_{1}=\Pi_{C_{1}} x_{0}$ and $C_{1}=C$, define the sequence $\left\{x_{n}\right\}$ as follows:

$$
\left\{\begin{array}{l}
v_{n}=\Pi_{C} J^{-1}\left(J x_{n}-\lambda_{n} A x_{n}\right) \\
z_{n}=J^{-1}\left(\alpha_{n, 0} J x_{n}+\sum_{i=1}^{\infty} \alpha_{n, j} J S_{i}^{n} v_{n}\right), \\
y_{n}=J^{-1}\left(\beta_{n} J x_{n}+\left(1-\beta_{n}\right) J z_{n}\right) \\
u_{n}=T_{r_{m, n}}^{f_{m}} T_{r_{m-1, n}}^{f_{m-1}} \ldots T_{r_{2, n}}^{f_{2}} T_{r_{1, n}}^{f_{1}} y_{n} \\
C_{n+1}=\left\{z \in C_{n}: \phi\left(z, u_{n}\right) \leq \phi\left(z, z_{n}\right) \leq \phi\left(z, x_{n}\right)+\theta_{n}\right\} \\
x_{n+1}=\Pi_{C_{n+1}} x_{0}, \quad \forall n \geq 1,
\end{array}\right.
$$

where $J$ is the duality mapping on $E, \theta_{n}=\sup _{q \in F}\left(k_{n}-\right.$ 1) $\phi\left(q, x_{n}\right)$, for each $i \geq 0,\left\{\alpha_{n, i}\right\}$ and $\left\{\beta_{n}\right\}$ are sequences in $[0,1],\left\{r_{j, n}\right\} \subset[d, \infty)$ for some $d>0$ and $\left\{\lambda_{n}\right\} \subset[a, b]$ for some $a, b$ with $0<a<b<c^{2} \alpha / 2$, where $\frac{1}{c}$ is the 2-uniformly convexity constant of $E$. If $\sum_{i=0}^{\infty} \alpha_{n, i}=$ 1 for all $n \geq 0$, $\liminf _{n \rightarrow \infty} \beta_{n}\left(1-\beta_{n}\right)>0$ and $\liminf _{n \rightarrow \infty} \alpha_{n, 0} \alpha_{n, i}>0$ for all $i \geq 1$, then $\left\{x_{n}\right\}$ converges strongly to $p \in F$, where $p=\Pi_{F} x_{0}$.

Proof. We first show that $C_{n+1}$ is closed and convex for each $n \geq 0$. Clearly $C_{1}=C$ is closed and convex. Suppose that $C_{n}$ is closed and convex for each $n \in \mathbb{N}$. Since for any $z \in C_{n}$, we known that

$$
\phi\left(z, u_{n}\right) \leq \phi\left(z, x_{n}\right)+\theta_{n}
$$

is equivalent to

$$
2\left\langle z, J x_{n}-J u_{n}\right\rangle \leq\left\|x_{n}\right\|^{2}-\left\|u_{n}\right\|^{2}+\theta_{n} .
$$

Hence, $C_{n+1}$ is closed and convex.

Next, we show that $F \subset C_{n}$ for all $n \geq 0$. Since by the convexity of $\|\cdot\|^{2}$, property of $\phi$, Lemma 2.9 and by uniformly quasi- $\phi$-asymptotically nonexpansive of $S_{n}$ for each $q \in F \subset C_{n}$, we have

$$
\begin{aligned}
& \phi\left(q, u_{n}\right)=\phi\left(q, T_{r_{m, n}}^{f_{m}} T_{r_{m-1, n}}^{f_{m-1}} \ldots T_{r_{2, n}}^{f_{2}} T_{r_{1, n}}^{f_{1}} y_{n}\right) \\
& \leq \phi\left(q, y_{n}\right) \\
& =\phi\left(q, J^{-1}\left(\beta_{n} J x_{n}+\left(1-\beta_{n}\right) J z_{n}\right)\right. \\
& =\|q\|^{2}-2\left\langle q, \beta_{n} J x_{n}+\left(1-\beta_{n}\right) J z_{n}\right\rangle \\
& +\left\|\beta_{n} J x_{n}+\left(1-\beta_{n}\right) J z_{n}\right\|^{2} \\
& \leq\|q\|^{2}-2 \beta_{n}\left\langle q, J x_{n}\right\rangle-2\left(1-\beta_{n}\right)\left\langle q, J z_{n}\right\rangle \\
& +\beta_{n}\left\|x_{n}\right\|^{2}+\left(1-\beta_{n}\right)\left\|z_{n}\right\|^{2} \\
& =\beta_{n} \phi\left(q, x_{n}\right)+\left(1-\beta_{n}\right) \phi\left(q, z_{n}\right) \text {, }
\end{aligned}
$$

and

$$
\begin{gathered}
\phi\left(q, z_{n}\right)=\phi\left(q, J^{-1}\left(\alpha_{n, 0} J x_{n}+\sum_{i=1}^{\infty} \alpha_{n, j} J S_{i}^{n} v_{n}\right)\right) \\
=\|q\|^{2}-2\left\langle q, \alpha_{n, 0} J x_{n}+\sum_{i=1}^{\infty} \alpha_{n, i} J S_{i}^{n} v_{n}\right\rangle \\
+\left\|\alpha_{n, 0} J x_{n}+\sum_{i=1}^{\infty} \alpha_{n, i} J S_{i}^{n} v_{n}\right\|^{2} \\
=\|q\|^{2}-2 \alpha_{n, 0}\left\langle q, J x_{n}\right\rangle-2 \sum_{i=1}^{\infty} \alpha_{n, i}\left\langle q, J S_{i}^{n} v_{n}\right\rangle \\
+\left\|\alpha_{n, 0} J x_{n}+\sum_{i=1}^{\infty} \alpha_{n, i} J S_{i}^{n} v_{n}\right\|^{2} \\
\leq\|q\|^{2}-2 \alpha_{n, 0}\left\langle q, J x_{n}\right\rangle-2 \sum_{i=1}^{\infty} \alpha_{n, i}\left\langle q, J S_{i}^{n} v_{n}\right\rangle \\
+\alpha_{n, 0}\left\|J x_{n}\right\|^{2}+\sum_{i=1}^{\infty} \alpha_{n, i}\left\|J S_{i}^{n} v_{n}\right\|^{2} \\
-\alpha_{n, 0} \alpha_{n, j} g\left\|J v_{n}-J S_{j}^{n} v_{n}\right\| \\
=\|q\|^{2}-2 \alpha_{n, 0}\left\langle q, J x_{n}\right\rangle+\alpha_{n, 0}\left\|J x_{n}\right\|^{2} \\
-2 \sum_{i=1}^{\infty} \alpha_{n, i}\left\langle q, J S_{i}^{n} v_{n}\right\rangle \\
+\sum_{i=1}^{\infty} \alpha_{n, i}\left\|J S_{i}^{n} v_{n}\right\|^{2} \\
-\alpha_{n, 0} \alpha_{n, j} g\left\|J v_{n}-J S_{j}^{n} v_{n}\right\| \\
=\alpha_{n, 0} \phi\left(q, x_{n}\right)+\sum_{i=1}^{\infty} \alpha_{n, i} \phi\left(q, S_{i}^{n} v_{n}\right) \\
-\alpha_{n, 0} \alpha_{n, j} g\left\|J v_{n}-J S_{j}^{n} v_{n}\right\| \\
\leq \alpha_{n, 0} \phi\left(q, x_{n}\right)+\sum_{i=1}^{\infty} \alpha_{n, i} k_{n} \phi\left(q, v_{n}\right) \\
-\alpha_{n, 0} \alpha_{n, j} g\left\|J v_{n}-J S_{j}^{n} v_{n}\right\| .
\end{gathered}
$$

It follows from Lemma 2.7, that

$$
\begin{aligned}
\phi\left(q, v_{n}\right)= & \phi\left(q, \Pi_{C} J^{-1}\left(J x_{n}-\lambda_{n} A x_{n}\right)\right) \\
\leq & \phi\left(q, J^{-1}\left(J x_{n}-\lambda_{n} A x_{n}\right)\right) \\
= & V\left(q, J x_{n}-\lambda_{n} A x_{n}\right) \\
\leq & V\left(q,\left(J x_{n}-\lambda_{n} A x_{n}\right)+\lambda_{n} A x_{n}\right) \\
& -2\left\langle J^{-1}\left(J x_{n}-\lambda_{n} A x_{n}\right)-q, \lambda_{n} A x_{n}\right\rangle \\
= & V\left(q, J x_{n}\right)-2 \lambda_{n}\left\langle J^{-1}\left(J x_{n}-\lambda_{n} A x_{n}\right)-q, A x_{n}\right\rangle \\
= & \phi\left(q, x_{n}\right)-2 \lambda_{n}\left\langle x_{n}-q, A x_{n}\right\rangle \\
& +2\left\langle J^{-1}\left(J x_{n}-\lambda_{n} A x_{n}\right)-x_{n},-\lambda_{n} A x_{n}\right\rangle .
\end{aligned}
$$

Since $q \in V I(A, C)$ and $A$ is an $\alpha$-inverse-strongly monotone mapping, we have

$$
\begin{aligned}
-2 \lambda_{n}\left\langle x_{n}-q, A x_{n}\right\rangle= & -2 \lambda_{n}\left\langle x_{n}-q, A x_{n}-A q\right\rangle \\
& -2 \lambda_{n}\left\langle x_{n}-q, A q\right\rangle \\
\leq & -2 \lambda_{n}\left\langle x_{n}-q, A x_{n}-A q\right\rangle \\
\leq & -2 \alpha \lambda_{n}\left\|A x_{n}-A q\right\|^{2} .
\end{aligned}
$$


By Lemma 2.2 and $\left\|A x_{n}\right\| \leq\left\|A x_{n}-A q\right\|, \forall q \in V I(A, C)$, we also have

$$
\begin{aligned}
2 & \left\langle J^{-1}\left(J x_{n}-\lambda_{n} A x_{n}\right)-x_{n},-\lambda_{n} A x_{n}\right\rangle \\
& =2\left\langle J^{-1}\left(J x_{n}-\lambda_{n} A x_{n}\right)-J^{-1}\left(J x_{n}\right),-\lambda_{n} A x_{n}\right\rangle \\
& \leq 2\left\|J^{-1}\left(J x_{n}-\lambda_{n} A x_{n}\right)-J^{-1}\left(J x_{n}\right)\right\|\left\|\lambda_{n} A x_{n}\right\| \\
& \leq \frac{4}{c^{2}}\left\|J J^{-1}\left(J x_{n}-\lambda_{n} A x_{n}\right)-J J^{-1}\left(J x_{n}\right)\right\|\left\|\lambda_{n} A x_{n}\right\| \\
& =\frac{4}{c^{2}}\left\|J x_{n}-\lambda_{n} A x_{n}-J x_{n}\right\|\left\|\lambda_{n} A x_{n}\right\| \\
& =\frac{4}{c^{2}}\left\|\lambda_{n} A x_{n}\right\|^{2} \\
& =\frac{4}{c^{2}} \lambda_{n}^{2}\left\|A x_{n}\right\|^{2} \\
& \leq \frac{4}{c^{2}} \lambda_{n}^{2}\left\|A x_{n}-A q\right\|^{2} .
\end{aligned}
$$

Substituting (3.5) and (3.6) into (3.4), we have

$$
\begin{aligned}
\phi\left(q, v_{n}\right) \leq & \phi\left(q, x_{n}\right)-2 \alpha \lambda_{n}\left\|A x_{n}-A q\right\|^{2} \\
& +\frac{4}{c^{2}} \lambda_{n}^{2}\left\|A x_{n}-A q\right\|^{2} \\
= & \phi\left(q, x_{n}\right)+2 \lambda_{n}\left(\frac{2}{c^{2}} \lambda_{n}-\alpha\right)\left\|A x_{n}-A q\right\|^{2} \\
\leq & \phi\left(q, x_{n}\right) .
\end{aligned}
$$

Substituting (3.7) into (3.3), we also have

$$
\begin{aligned}
\phi\left(q, z_{n}\right) \leq & \alpha_{n, 0} \phi\left(q, x_{n}\right)+\sum_{i=1}^{\infty} \alpha_{n, i} k_{n} \phi\left(q, x_{n}\right) \\
& -\alpha_{n, 0} \alpha_{n, j} g\left\|J v_{n}-J S_{j}^{n} v_{n}\right\| \\
\leq & \alpha_{n, 0} k_{n} \phi\left(q, x_{n}\right)+\sum_{i=1}^{\infty} \alpha_{n, i} k_{n} \phi\left(q, x_{n}\right) \\
& -\alpha_{n, 0} \alpha_{n, j} g\left\|J v_{n}-J S_{j}^{n} v_{n}\right\| \\
= & k_{n} \phi\left(q, x_{n}\right)-\alpha_{n, 0} \alpha_{n, j} g\left\|J v_{n}-J S_{j}^{n} v_{n}\right\| \\
\leq & \phi\left(q, x_{n}\right)+\sup _{q \in F}\left(k_{n}-1\right) \phi\left(q, x_{n}\right) \\
& -\alpha_{n, 0} \alpha_{n, j} g\left\|J v_{n}-J S_{j}^{n} v_{n}\right\| \\
= & \phi\left(q, x_{n}\right)+\theta_{n}-\alpha_{n, 0} \alpha_{n, j} g\left\|J v_{n}-J S_{j}^{n} v_{n}\right\| \\
\leq & \phi\left(q, x_{n}\right)+\theta_{n}
\end{aligned}
$$

and substituting (3.8) into (3.2), we obtain

$$
\phi\left(q, u_{n}\right) \leq \phi\left(q, x_{n}\right)+\theta_{n} .
$$

Thus, this show that $q \in C_{n+1}$ implies that $F \subset C_{n+1}$ and hence, $F \subset C_{n}$ for all $n \geq 0$. This implies that the sequence $\left\{x_{n}\right\}$ is well defined. From definition of $C_{n+1}$ that $x_{n}=\Pi_{C_{n}} x_{0}$ and $x_{n+1}=\Pi_{C_{n+1} x_{0}}, \in C_{n+1} \subset C_{n}$ we have

$$
\phi\left(x_{n}, x_{0}\right) \leq \phi\left(x_{n+1}, x_{0}\right), \quad \forall n \geq 0 .
$$

Form Lemma 2.6, it follows that

$$
\begin{aligned}
\phi\left(x_{n}, x_{0}\right) & =\phi\left(\Pi_{C_{n}} x_{0}, x_{0}\right) \\
& \leq \phi\left(q, x_{0}\right)-\phi\left(q, x_{n}\right) \\
& \leq \phi\left(q, x_{0}\right), \quad \forall q \in F .
\end{aligned}
$$

By (3.10) and (3.11), then $\left\{\phi\left(x_{n}, x_{0}\right)\right\}$ are nondecreasing and bounded. So, we obtain that $\lim _{n \rightarrow \infty} \phi\left(x_{n}, x_{0}\right)$ exists.
In particular, by (1.5), the sequence $\left\{\left(\left\|x_{n}\right\|-\left\|x_{0}\right\|\right)^{2}\right\}$ is bounded. This implies $\left\{x_{n}\right\}$ is also bounded. We denote

$$
M:=\sup _{n \geq 0}\left\{\left\|x_{n}\right\|\right\}<\infty .
$$

Moreover, by the definition of $\theta_{n}$ and (3.12), it follows that

$$
\theta_{n} \rightarrow 0 \text { as } n \rightarrow \infty \text {. }
$$

Next, we show that $\left\{x_{n}\right\}$ is a Cauchy sequence in $C$. Since $x_{m}=\Pi_{C_{m}} x_{0} \in C_{m} \subset C_{n}$, for $m>n$, by Lemma 2.6, we have

$$
\begin{aligned}
\phi\left(x_{m}, x_{n}\right) & =\phi\left(x_{m}, \Pi_{C_{n}} x_{0}\right) \\
& \leq \phi\left(x_{m}, x_{0}\right)-\phi\left(\Pi_{C_{n}} x_{0}, x_{0}\right) \\
& =\phi\left(x_{m}, x_{0}\right)-\phi\left(x_{n}, x_{0}\right) .
\end{aligned}
$$

Since $\lim _{n \rightarrow \infty} \phi\left(x_{n}, x_{0}\right)$ exists and we taking $m, n \rightarrow \infty$ then, we get $\phi\left(x_{m}, x_{n}\right) \rightarrow 0$. From Lemma 2.4, we have $\lim _{n \rightarrow \infty}\left\|x_{m}-x_{n}\right\|=0$. Thus $\left\{x_{n}\right\}$ is a Cauchy sequence and by the completeness of $E$ and there exist a point $p \in C$ such that

$$
x_{n} \rightarrow p \text { as } n \rightarrow \infty .
$$

Now, we claim that $\left\|J u_{n}-J x_{n}\right\| \rightarrow 0$, as $n \rightarrow \infty$. By definition of $x_{n}=\Pi_{C_{n}} x_{0}$, we have

$$
\begin{aligned}
\phi\left(x_{n+1}, x_{n}\right) & =\phi\left(x_{n+1}, \Pi_{C_{n}} x_{0}\right) \\
& \leq \phi\left(x_{n+1}, x_{0}\right)-\phi\left(\Pi_{C_{n}} x_{0}, x_{0}\right) \\
& =\phi\left(x_{n+1}, x_{0}\right)-\phi\left(x_{n}, x_{0}\right) .
\end{aligned}
$$

Since $\lim _{n \rightarrow \infty} \phi\left(x_{n}, x_{0}\right)$ exists, we also have

$$
\lim _{n \rightarrow \infty} \phi\left(x_{n+1}, x_{n}\right)=0 .
$$

Again form Lemma 2.4, that

$$
\lim _{n \rightarrow \infty}\left\|x_{n+1}-x_{n}\right\|=0 .
$$

From $J$ is uniformly norm-to-norm continuous on bounded subsets of $E$, we obtain

$$
\lim _{n \rightarrow \infty}\left\|J x_{n+1}-J x_{n}\right\|=0 .
$$

Since $x_{n+1}=\Pi_{C_{n+1}} x_{0} \in C_{n+1} \subset C_{n}$ and the definition of $C_{n+1}$, we have

$$
\phi\left(x_{n+1}, u_{n}\right) \leq \phi\left(x_{n+1}, x_{n}\right)+\theta_{n} .
$$

By (3.13) and (3.15), that

$$
\lim _{n \rightarrow \infty} \phi\left(x_{n+1}, u_{n}\right)=0 .
$$

Applying Lemma 2.4, we have

$$
\lim _{n \rightarrow \infty}\left\|x_{n+1}-u_{n}\right\|=0 .
$$

Since

$$
\begin{aligned}
\left\|u_{n}-x_{n}\right\| & =\left\|u_{n}-x_{n+1}+x_{n+1}-x_{n}\right\| \\
& \leq\left\|u_{n}-x_{n+1}\right\|+\left\|x_{n+1}-x_{n}\right\| .
\end{aligned}
$$

It follows from (3.23) and (3.19), that

$$
\lim _{n \rightarrow \infty}\left\|u_{n}-x_{n}\right\|=0 .
$$


Since $J$ is uniformly norm-to-norm continuous on bounded subsets of $E$, we also have

$$
\lim _{n \rightarrow \infty}\left\|J u_{n}-J x_{n}\right\|=0 .
$$

Next, we will show that $x_{n} \rightarrow p \in F:=\cap_{j=1}^{m} E P\left(f_{j}\right) \cap$ $\left(\cap_{i=1}^{\infty} F\left(S_{i}\right)\right) \cap \operatorname{VI}(A, C)$.

(i) We show that $x_{n} \rightarrow p \in \cap_{i=1}^{\infty} F\left(S_{i}\right)$. It follows from definition of $x_{n+1}=\Pi_{C_{n+1}} x_{0} \in C_{n+1} \subset C_{n}$, we have

$$
\phi\left(x_{n+1}, z_{n}\right) \leq \phi\left(x_{n+1}, x_{n}\right)+\theta_{n}, \quad \forall n \geq 1 .
$$

By (3.13) and (3.15), that

$$
\lim _{n \rightarrow \infty} \phi\left(x_{n+1}, z_{n}\right)=0 .
$$

Form Lemma 2.4, that

$$
\lim _{n \rightarrow \infty}\left\|x_{n+1}-z_{n}\right\|=0
$$

Since $J$ is uniformly norm-to-norm continuous, we obtain

$$
\lim _{n \rightarrow \infty}\left\|J x_{n+1}-J z_{n}\right\|=0 .
$$

From (3.45), we note that

$$
\begin{aligned}
\left\|J x_{n+1}-J z_{n}\right\|= & \left\|J x_{n+1}-\left(\alpha_{n, 0} J x_{n}+\sum_{i=1}^{\infty} \alpha_{n, i} J S_{i}^{n} v_{n}\right)\right\| \\
= & \| \alpha_{n, 0} J x_{n+1}-\alpha_{n, 0} J x_{n}+\sum_{i=1}^{\infty} \alpha_{n, i} J x_{n+1} \\
& -\sum_{i=1}^{\infty} \alpha_{n, i} J S_{i}^{n} v_{n} \| \\
= & \| \alpha_{n, 0}\left(J x_{n+1}-J x_{n}\right) \\
& +\sum_{i=1}^{\infty} \alpha_{n, i}\left(J x_{n+1}-J S_{i}^{n} v_{n}\right) \| \\
= & \| \sum_{i=1}^{\infty} \alpha_{n, i}\left(J x_{n+1}-J S_{i}^{n} v_{n}\right) \\
& -\alpha_{n, 0}\left(J x_{n}-J x_{n+1}\right) \| \\
\geq & \sum_{i=1}^{\infty} \alpha_{n, i}\left\|J x_{n+1}-J S_{i}^{n} v_{n}\right\| \\
& -\alpha_{n, 0}\left\|J x_{n}-J x_{n+1}\right\|
\end{aligned}
$$

and hence

$$
\begin{aligned}
& \left\|J x_{n+1}-J S_{i}^{n} v_{n}\right\| \leq \frac{1}{\sum_{i=1}^{\infty} \alpha_{n, i}} \\
& \quad \times\left(\left\|J x_{n+1}-J z_{n}\right\|+\alpha_{n, 0}\left\|J x_{n}-J x_{n+1}\right\|\right) .
\end{aligned}
$$

From (3.17), (3.24) and $\liminf _{n \rightarrow \infty} \sum_{i=1}^{\infty} \alpha_{n, i}>0$, we get

$$
\lim _{n \rightarrow \infty}\left\|J x_{n+1}-J S_{i}^{n} v_{n}\right\|=0 .
$$

Since $J^{-1}$ is uniformly norm-to-norm continuous on bounded sets, we have

$$
\lim _{n \rightarrow \infty}\left\|x_{n+1}-S_{i}^{n} v_{n}\right\|=0 .
$$

Using the triangle inequality, that

$$
\begin{aligned}
\left\|x_{n}-S_{i}^{n} v_{n}\right\| & =\left\|x_{n}-x_{n+1}+x_{n+1}-S_{i}^{n} v_{n}\right\| \\
& \leq\left\|x_{n}-x_{n+1}\right\|+\left\|x_{n+1}-S_{i}^{n} v_{n}\right\| .
\end{aligned}
$$

From (3.23) and (3.27), we have

$$
\lim _{n \rightarrow \infty}\left\|x_{n}-S_{i}^{n} v_{n}\right\|=0
$$

On the other hand, we observe that

$$
\begin{aligned}
\phi\left(q, x_{n}\right)-\phi\left(q, u_{n}\right)+\theta_{n}= & \left\|x_{n}\right\|^{2}-\left\|u_{n}\right\|^{2} \\
& -2\left\langle q, J x_{n}-J u_{n}\right\rangle+\theta_{n} .
\end{aligned}
$$

It follows from $\theta_{n} \rightarrow 0,\left\|x_{n}-u_{n}\right\| \rightarrow 0$ and $\left\|J x_{n}-J u_{n}\right\| \rightarrow$ 0 , that

$$
\phi\left(q, x_{n}\right)-\phi\left(q, u_{n}\right)+\theta_{n} \rightarrow 0 \text { as } n \rightarrow \infty .
$$

From (3.2), (3.3) and (3.7), we compute

$$
\begin{aligned}
& \phi\left(q, u_{n}\right) \leq \phi\left(q, y_{n}\right) \\
& \leq \beta_{n} \phi\left(q, x_{n}\right)+\left(1-\beta_{n}\right) \phi\left(q, z_{n}\right) \\
& \leq \beta_{n} \phi\left(q, x_{n}\right)+\left(1-\beta_{n}\right)\left[\alpha_{n, 0} \phi\left(q, x_{n}\right)\right. \\
& +\sum_{i=1}^{\infty} \alpha_{n, i} k_{n} \phi\left(q, v_{n}\right) \\
& \left.-\alpha_{n, 0} \alpha_{n, j} g\left\|J v_{n}-J S_{j}^{n} v_{n}\right\|\right] \\
& =\beta_{n} \phi\left(q, x_{n}\right)+\left(1-\beta_{n}\right) \alpha_{n, 0} \phi\left(q, x_{n}\right) \\
& +\left(1-\beta_{n}\right) \sum_{i=1}^{\infty} \alpha_{n, i} k_{n} \phi\left(q, v_{n}\right) \\
& -\left(1-\beta_{n}\right) \alpha_{n, 0} \alpha_{n, j} g\left\|J v_{n}-J S_{j}^{n} v_{n}\right\| \\
& \leq \beta_{n} \phi\left(q, x_{n}\right)+\left(1-\beta_{n}\right) \alpha_{n, 0} \phi\left(q, x_{n}\right) \\
& +\left(1-\beta_{n}\right) \sum_{i=1}^{\infty} \alpha_{n, i} k_{n} \phi\left(q, v_{n}\right) \\
& \leq \beta_{n} \phi\left(q, x_{n}\right)+\left(1-\beta_{n}\right) \alpha_{n, 0} \phi\left(q, x_{n}\right) \\
& +\left(1-\beta_{n}\right) \sum_{i=1}^{\infty} \alpha_{n, i} k_{n}\left[\phi\left(q, x_{n}\right)\right. \\
& \left.-2 \lambda_{n}\left(\alpha-\frac{2}{c^{2}} \lambda_{n}\right)\left\|A x_{n}-A q\right\|^{2}\right] \\
& \leq \beta_{n} \phi\left(q, x_{n}\right)+\left(1-\beta_{n}\right) \alpha_{n, 0} k_{n} \phi\left(q, x_{n}\right) \\
& +\left(1-\beta_{n}\right) \sum_{i=1}^{\infty} \alpha_{n, i} k_{n} \phi\left(q, x_{n}\right) \\
& -\left(1-\beta_{n}\right) \sum_{i=1}^{\infty} \alpha_{n, i} k_{n} 2 \lambda_{n} \\
& \times\left(\alpha-\frac{2}{c^{2}} \lambda_{n}\right)\left\|A x_{n}-A q\right\|^{2} \\
& =\beta_{n} k_{n} \phi\left(q, x_{n}\right)+\left(1-\beta_{n}\right) k_{n} \phi\left(q, x_{n}\right) \\
& -\left(1-\beta_{n}\right) \sum_{i=1}^{\infty} \alpha_{n, i} k_{n} 2 \lambda_{n} \\
& \times\left(\alpha-\frac{2}{c^{2}} \lambda_{n}\right)\left\|A x_{n}-A q\right\|^{2} \\
& \leq k_{n} \phi\left(q, x_{n}\right)-\left(1-\beta_{n}\right) \sum_{i=1}^{\infty} \alpha_{n, i} k_{n} 2 \lambda_{n} \\
& \left.\times\left(\alpha-\frac{2}{c^{2}} \lambda_{n}\right)\left\|A x_{n}-A q\right\|^{2}\right] \\
& \leq \phi\left(q, x_{n}\right)+\sup _{q \in F}\left(k_{n}-1\right) \phi\left(q, x_{n}\right) \\
& -\left(1-\beta_{n}\right) \sum_{i=1}^{\infty} \alpha_{n, i} k_{n} 2 \lambda_{n} \\
& \times\left(\alpha-\frac{2}{c^{2}} \lambda_{n}\right)\left\|A x_{n}-A q\right\|^{2} \\
& \leq \phi\left(q, x_{n}\right)+\theta_{n}-\left(1-\beta_{n}\right) \sum_{i=1}^{\infty} \alpha_{n, i} k_{n} 2 \lambda_{n} \\
& \times\left(\alpha-\frac{2}{c^{2}} \lambda_{n}\right)\left\|A x_{n}-A q\right\|^{2}
\end{aligned}
$$

and hence

$$
\begin{aligned}
2 a\left(\alpha-\frac{2 b}{c^{2}}\right)\left\|A x_{n}-A q\right\|^{2} \leq & 2 \lambda_{n}\left(\alpha-\frac{2}{c^{2}} \lambda_{n}\right)\left\|A x_{n}-A q\right\|^{2} \\
\leq & \frac{1}{\left(1-\beta_{n}\right) \sum_{i=1}^{\infty} \alpha_{n, i} k_{n}}\left(\phi\left(q, x_{n}\right)\right. \\
& \left.-\phi\left(q, u_{n}\right)+\theta_{n}\right) .
\end{aligned}
$$


From (3.29), $\left\{\lambda_{n}\right\} \subset[a, b]$ for some $a, b$ with $0<a<b<$ $c^{2} \alpha / 2, \liminf _{n \rightarrow \infty}\left(1-\beta_{n}\right)>0$ and $\liminf _{n \rightarrow \infty} \alpha_{n, 0} \alpha_{n, i}>$ 0 , for $i \geq 0$ and $k_{n} \rightarrow 1$ as $n \rightarrow \infty$, we obtain that

$$
\lim _{n \rightarrow \infty}\left\|A x_{n}-A q\right\|=0 .
$$

From Lemma 2.6, Lemma 2.7 and (3.6), we compute

$$
\begin{aligned}
\phi\left(x_{n}, v_{n}\right)= & \phi\left(x_{n}, \Pi_{C} J^{-1}\left(J x_{n}-\lambda_{n} A x_{n}\right)\right) \\
\leq & \phi\left(x_{n}, J^{-1}\left(J x_{n}-\lambda_{n} A x_{n}\right)\right) \\
= & V\left(x_{n}, J x_{n}-\lambda_{n} A x_{n}\right) \\
\leq & \left.V\left(x_{n}, J x_{n}-\lambda_{n} A x_{n}\right)+\lambda_{n} A x_{n}\right) \\
& -2\left\langle J^{-1}\left(J x_{n}-\lambda_{n} A x_{n}\right)-x_{n}, \lambda_{n} A x_{n}\right\rangle \\
= & \phi\left(x_{n}, x_{n}\right)+2\left\langle J^{-1}\left(J x_{n}-\lambda_{n} A x_{n}\right)-x_{n},-\lambda_{n} A x_{n}\right\rangle \\
= & 2\left\langle J^{-1}\left(J x_{n}-\lambda_{n} A x_{n}\right)-x_{n},-\lambda_{n} A x_{n}\right\rangle \\
\leq & \frac{4 \lambda_{n}^{2}}{c^{2}}\left\|A x_{n}-A q\right\|^{2} \\
\leq & \frac{4 b^{2}}{c^{2}}\left\|A x_{n}-A q\right\|^{2} .
\end{aligned}
$$

Applying Lemma 2.4 and (3.31) that

$$
\lim _{n \rightarrow \infty}\left\|x_{n}-v_{n}\right\|=0
$$

and we also obtain

$$
\lim _{n \rightarrow \infty}\left\|J x_{n}-J v_{n}\right\|=0 .
$$

From $S_{i}^{n}$ is continuous, for any $i \geq 1$

$$
\lim _{n \rightarrow \infty}\left\|S_{i}^{n} x_{n}-S_{i}^{n} v_{n}\right\|=0 .
$$

Again by the triangle inequality, we get

$$
\left\|x_{n}-S_{i}^{n} x_{n}\right\| \leq\left\|x_{n}-S_{i}^{n} v_{n}\right\|+\left\|S_{i}^{n} v_{n}-S_{i}^{n} x_{n}\right\| .
$$

From (3.28) and (3.34), we have

$$
\lim _{n \rightarrow \infty}\left\|x_{n}-S_{i}^{n} x_{n}\right\|=0, \quad \forall i \geq 1 .
$$

By using the triangle inequality, we have

$$
\left\|p-S_{i}^{n} x_{n}\right\| \leq\left\|p-x_{n}\right\|+\left\|x_{n}-S_{i}^{n} x_{n}\right\| .
$$

That is

$$
\lim _{n \rightarrow \infty}\left\|p-S_{i}^{n} x_{n}\right\|=0, \quad \forall i \geq 1 .
$$

By the assumption that $\forall i \geq 1, S_{i}$ is uniformly $L_{i}$-Lipschitz continuous, hence we have.

$$
\begin{aligned}
\left\|S_{i}^{n+1} x_{n}-S_{i}^{n} x_{n}\right\| \leq & \left\|S_{i}^{n+1} x_{n}-S_{i}^{n+1} x_{n+1}\right\| \\
& +\left\|S_{i}^{n+1} x_{n+1}-p\right\|+\left\|p-S_{i}^{n} x_{n}\right\| \\
\leq & \left(L_{i}+1\right)\left\|x_{n+1}-x_{n}\right\| \\
& +\left\|S_{i}^{n+1} x_{n+1}-p\right\|+\left\|p-S_{i}^{n} x_{n}\right\| .
\end{aligned}
$$

By (3.23) and (3.36), it follows that $\left\|S_{i}^{n+1} x_{n}-S_{i}^{n} x_{n}\right\| \rightarrow 0$. From $S_{i}^{n} x_{n} \rightarrow p$, we have $S_{i}^{n+1} x_{n} \rightarrow p$, that is $S_{i} S_{i}^{n} x_{n} \rightarrow p$. In view of closeness of $S_{i}$, we have $S_{i} p=p$, for all $i \geq 1$. This imply that $p \in \cap_{i=1}^{\infty} F\left(S_{i}\right)$.

(ii) We show that $x_{n} \rightarrow p \in \cap_{j=1}^{m} E P\left(f_{j}\right)$. From Lemma 2.13 and $u_{n}=\Omega_{n}^{m} y_{n}$, when $\Omega_{n}^{j}=$
$T_{r_{j, n}}^{f_{j}} T_{r_{j-1, n}}^{f_{j-1}} \ldots T_{r_{2, n}}^{f_{2}} T_{r_{1, n}}^{f_{1}}, j=1,2,3, \ldots, m, \Omega_{n}^{0}=I$, for $q \in F$, we observe that

$$
\begin{aligned}
\phi\left(u_{n}, \Omega_{n}^{j} y_{n}\right) \leq & \phi\left(q, \Omega_{n}^{j} y_{n}\right)-\phi\left(q, u_{n}\right) \\
\leq & \phi\left(q, x_{n}\right)-\phi\left(q, u_{n}\right)+\theta_{n} \\
= & \|q\|^{2}-2\left\langle q, J x_{n}\right\rangle+\left\|x_{n}\right\|^{2} \\
& -\left(\|q\|^{2}-2\left\langle q, J u_{n}\right\rangle+\left\|u_{n}\right\|^{2}\right)+\theta_{n} \\
= & \left\|x_{n}\right\|^{2}-\left\|u_{n}\right\|^{2}-2\left\langle q, J x_{n}-J u_{n}\right\rangle+\theta_{n} \\
\leq & \left\|x_{n}-u_{n}\right\|\left(\left\|x_{n}+u_{n}\right\|\right) \\
& +2\|q\|\left\|J x_{n}-J u_{n}\right\|+\theta_{n} .
\end{aligned}
$$

From (3.20), (3.21), $\theta_{n} \rightarrow 0$ as $n \rightarrow \infty$ and Lemma 2.4, we get

$$
\lim _{n \rightarrow \infty}\left\|u_{n}-\Omega_{n}^{j} y_{n}\right\|=0, \forall j=1,2,3, \ldots, m .
$$

By using triangle inequality, we have

$$
\left\|x_{n}-\Omega_{n}^{j} y_{n}\right\| \leq\left\|x_{n}-u_{n}\right\|+\left\|u_{n}-\Omega_{n}^{j} y_{n}\right\| .
$$

From (3.20) and (3.39), we have

$$
\lim _{n \rightarrow \infty}\left\|x_{n}-\Omega_{n}^{j} y_{n}\right\|=0, \quad \forall j=1,2,3, \ldots, m .
$$

Again by using triangle inequality, we have

$$
\left\|\Omega_{n}^{j} y_{n}-\Omega_{n}^{j-1} y_{n}\right\| \leq\left\|\Omega_{n}^{j} y_{n}-x_{n}\right\|+\left\|x_{n}-\Omega_{n}^{j-1} y_{n}\right\| .
$$

From (3.40),we also have

$$
\lim _{n \rightarrow \infty}\left\|\Omega_{n}^{j} y_{n}-\Omega_{n}^{j-1} y_{n}\right\|=0, \quad \forall j=1,2,3, \ldots, m .
$$

Since J is uniformly norm-to-norm continuous, we obtain

$$
\lim _{n \rightarrow \infty}\left\|J \Omega_{n}^{j} y_{n}-J \Omega_{n}^{j-1} y_{n}\right\|=0, \quad \forall j=1,2,3, \ldots, m .
$$

From $r_{j, n}>0$ we have $\frac{\left\|J \Omega_{n}^{j} y_{n}-J \Omega_{n}^{j-1} y_{n}\right\|}{r_{j, n}} \rightarrow 0$ as $n \rightarrow \infty$, $\forall j=1,2,3, \ldots, m$, and

$$
f_{j}\left(\Omega_{n}^{j} y_{n}, y\right)+\frac{1}{r_{j, n}}\left\langle y-\Omega_{n}^{j} y_{n}, J \Omega_{n}^{j} y_{n}-J \Omega_{n}^{j-1} y_{n}\right\rangle \geq 0, \forall y \in C .
$$

By (A2), that

$$
\begin{aligned}
\| y & -\Omega_{n}^{j} y_{n} \| \frac{\left\|J \Omega_{n}^{j} y_{n}-J \Omega_{n}^{j-1} y_{n}\right\|}{r_{n}} \\
& \geq \frac{1}{r_{j, n}}\left\langle y-\Omega_{n}^{j} y_{n}, J \Omega_{n}^{j} y_{n}-J \Omega_{n}^{j-1} y_{n}\right\rangle \\
& \geq-f_{j}\left(\Omega_{n}^{j} y_{n}, y\right) \\
& \geq f_{j}\left(y, \Omega_{n}^{j} y_{n}\right), \quad \forall y \in C,
\end{aligned}
$$

and $\Omega_{n}^{j} y_{n} \rightarrow p$ we get $f(y, p) \leq 0$ for all $y \in C$. For $0<$ $t<1$, define $y_{t}=t y+(1-t) p$. Then $y_{t} \in C$ which imply that $f_{j}\left(y_{t}, p\right) \leq 0$. From (A1), we obtain that

$$
0=f_{j}\left(y_{t}, y_{t}\right) \leq t f_{j}\left(y_{t}, y\right)+(1-t) f_{j}\left(y_{t}, p\right) \leq t f_{j}\left(y_{t}, y\right) .
$$

Thus $f_{j}\left(y_{t}, y\right) \geq 0$. From (A3), we have $f_{j}(p, y) \geq 0$ for all $y \in C$ and $j=1,2,3, \ldots, m$. Hence $p \in E P\left(f_{j}\right), \forall j=$ $1,2,3, \ldots, m$. This imply that $p \in \cap_{j=1}^{m} E P\left(f_{j}\right)$. 
(iii) We show that $x_{n} \rightarrow p \in V I(A, C)$. Indeed, define $B \subset E \times E^{*}$ by

$$
B v=\left\{\begin{array}{l}
A v+N_{C}(v), \quad v \in C \\
\emptyset, \quad v \notin C
\end{array}\right.
$$

By Lemma 2.8, $B$ is maximal monotone and $B^{-1} 0=$ $V I(A, C)$. Let $(v, w) \in G(B)$. Since $w \in B v=A v+N_{C}(v)$, we get $w-A v \in N_{C}(v)$. From $v_{n} \in C$, we have

$$
\left\langle v-v_{n}, w-A v\right\rangle \geq 0 \text {. }
$$

On the other hand, since $v_{n}=\Pi_{C} J^{-1}\left(J x_{n}-\lambda_{n} A x_{n}\right)$. Then by Lemma 2.5 , we have

$$
\left\langle v-v_{n}, J v_{n}-\left(J x_{n}-\lambda_{n} A x_{n}\right)\right\rangle \geq 0,
$$

and thus

$$
\left\langle v-v_{n}, \frac{J x_{n}-J v_{n}}{\lambda_{n}}-A x_{n}\right\rangle \leq 0 .
$$

It follows from (3.43), (3.44) and $A$ is monotone and $\frac{1}{\alpha}$ Lipschitz continuous, that

$$
\begin{aligned}
\left\langle v-v_{n}, w\right\rangle \geq & \left\langle v-v_{n}, A v\right\rangle \\
\geq & \left\langle v-v_{n}, A v\right\rangle+\left\langle v-v_{n}, \frac{J x_{n}-J v_{n}}{\lambda_{n}}-A x_{n}\right\rangle \\
= & \left\langle v-v_{n}, A v-A x_{n}\right\rangle+\left\langle v-z v_{n}, \frac{J x_{n}-J v_{n}}{\lambda_{n}}\right\rangle \\
= & \left\langle v-v_{n}, A v-A v_{n}\right\rangle+\left\langle v-v_{n}, A v_{n}-A x_{n}\right\rangle \\
& +\left\langle v-v_{n}, \frac{J x_{n}-J v_{n}}{\lambda_{n}}\right\rangle \\
\geq & -\left\|v-v_{n}\right\| \frac{\left\|v_{n}-x_{n}\right\|}{\alpha}-\left\|v-v_{n}\right\| \frac{\left\|x_{n}-J v_{n}\right\|}{a} \\
\geq & -H\left(\frac{\left\|v_{n}-x_{n}\right\|}{\alpha}+\frac{\left\|x_{n}-J v_{n}\right\|}{a}\right),
\end{aligned}
$$

where $H=\sup _{n>1}\left\|v-v_{n}\right\|$. Take the limit as $n \rightarrow$ $\infty$, (3.32) and (3.33), we obtain $\langle v-p, w\rangle \geq 0$. By the maximality of $B$ we have $p \in B^{-1} 0$, that is $p \in V I(A, C)$.

Finally, we show that $p=\Pi_{F} x_{0}$. From $x_{n}=\Pi_{C_{n}} x_{0}$, we have $\left\langle J x_{0}-J x_{n}, x_{n}-z\right\rangle \geq 0, \forall z \in C_{n}$. Since $F \subset C_{n}$, we also have

$$
\left\langle J x_{0}-J x_{n}, x_{n}-y\right\rangle \geq 0, \quad \forall y \in F .
$$

Taking limit $n \rightarrow \infty$, we obtain

$$
\left\langle J x_{0}-J p, p-y\right\rangle \geq 0, \quad \forall y \in F .
$$

By Lemma 2.5, we can conclude that $p=\Pi_{F} x_{0}$ and $x_{n} \rightarrow$ $p$ as $n \rightarrow \infty$. This completes the proof.

If $S_{i}=S$ for each $i \in \mathbb{N}$, then Theorem 3.1 is reduced to the following Corollary.

Corollary 3.2. Let $C$ be a nonempty closed and convex subset of a 2-uniformly convex and uniformly smooth Banach space E. For each $j=1,2, \ldots$, m let $f_{j}$ be a bifunction from $C \times C$ to $\mathbb{R}$ which satisfies conditions (A1)-(A4). Let $A$ be an $\alpha$-inverse-strongly monotone mapping of $C$ into $E^{*}$ satisfying $\|A y\| \leq\|A y-A u\|, \quad \forall y \in C$ and $u \in V I(A, C) \neq \emptyset$. Let $S: C \rightarrow C$ be a closed LLipschitz continuous and quasi- $\phi$-asymptotically nonexpansive mappings with a sequence $\left\{k_{n}\right\} \subset[1, \infty), k_{n} \rightarrow 1$ such that $F:=(F(S)) \cap\left(\cap_{j=1}^{m} E P\left(f_{j}\right)\right) \cap(V I(A, C))$ is a nonempty and bounded subset in $C$. For an initial point $x_{0} \in E$ with $x_{1}=\Pi_{C_{1}} x_{0}$ and $C_{1}=C$, we define the sequence $\left\{x_{n}\right\}$ as follows:

$$
\left\{\begin{array}{l}
v_{n}=\Pi_{C} J^{-1}\left(J x_{n}-\lambda_{n} A x_{n}\right), \\
z_{n}=J^{-1}\left(\alpha_{n} J x_{n}+\left(1-\alpha_{n}\right) J S^{n} v_{n}\right), \\
y_{n}=J^{-1}\left(\beta_{n} J x_{n}+\left(1-\beta_{n}\right) J z_{n}\right), \\
u_{n}=T_{r_{m, n}}^{f_{m}} T_{r_{m-1, n}}^{f_{m-1}} \ldots T_{r_{2, n}}^{f_{2}} T_{r_{1, n}}^{f_{1}} y_{n}, \\
C_{n+1}=\left\{z \in C_{n}: \phi\left(z, u_{n}\right) \leq \phi\left(z, z_{n}\right) \leq \phi\left(z, x_{n}\right)+\theta_{n}\right\}, \\
x_{n+1}=\Pi_{C_{n+1}} x_{0}, \quad \forall n \geq 1,
\end{array}\right.
$$

where $J$ is the duality mapping on $E, \theta_{n}=\sup _{q \in F}\left(k_{n}-\right.$ 1) $\phi\left(q, x_{n}\right),\left\{\alpha_{n}\right\},\left\{\beta_{n}\right\}$ are sequences in $[0,1],\left\{r_{j, n}\right\} \subset[d, \infty)$ for some $d>0$ and $\left\{\lambda_{n}\right\} \subset[a, b]$ for some $a, b$ with $0<a<$ $b<c^{2} \alpha / 2$, where $\frac{1}{c}$ is the 2-uniformly convexity constant of $E$. If $\liminf _{n \rightarrow \infty}\left(1-\beta_{n}\right)>0$ and $\liminf _{n \rightarrow \infty} \alpha_{n}(1-$ $\left.\alpha_{n}\right)>0$, then $\left\{x_{n}\right\}$ converges strongly to $p \in F$, where $p=$ $\Pi_{F} x_{0}$.

For a special case that $i=1,2$, we can obtain the following results on a pair of quasi- $\phi$-asymptotically nonexpansive mappings immediately from Theorem 3.1.

Corollary 3.3. Let $C$ be a nonempty closed and convex subset of a 2-uniformly convex and uniformly smooth Banach space E. For each $j=1,2, \ldots$, m let $f_{j}$ be a bifunction from $C \times C$ to $\mathbb{R}$ which satisfies conditions (A1)(A4). Let $A$ be an $\alpha$-inverse-strongly monotone mapping of $C$ into $E^{*}$ satisfying $\|A y\| \leq\|A y-A u\|, \quad \forall y \in C$ and $u \in V I(A, C) \neq \emptyset$. Let $S, T: C \rightarrow C$ be two closed quasi$\phi$-asymptotically nonexpansive mappings and $L_{S}, L_{T^{-}}$ Lipschitz continuous, respectively with a sequence $\left\{k_{n}\right\} \subset$ $[1, \infty), k_{n} \rightarrow 1$ such that $F:=F(S) \cap F(T) \cap\left(\cap_{j=1}^{m} E P\left(f_{j}\right)\right) \cap$ $V I(A, C)$ is a nonempty and bounded subset in $C$. For an initial point $x_{0} \in E$ with $x_{1}=\Pi_{C_{1}} x_{0}$ and $C_{1}=C$, we define the sequence $\left\{x_{n}\right\}$ as follows:

$$
\left\{\begin{array}{l}
v_{n}=\Pi_{C} J^{-1}\left(J x_{n}-\lambda_{n} A x_{n}\right), \\
z_{n}=J^{-1}\left(\alpha_{n} J x_{n}+\beta_{n} J S^{n} v_{n}+\gamma_{n} J T^{n} v_{n}\right), \\
y_{n}=J^{-1}\left(\delta_{n} J x_{n}+\left(1-\delta_{n}\right) J z_{n}\right), \\
u_{n}=T_{r_{m, n}}^{f_{m}} T_{r_{m-1, n}}^{f_{m-1}} \ldots T_{r_{2, n}}^{f_{2}} T_{r_{1, n}}^{f_{1}} y_{n}, \\
C_{n+1}=\left\{z \in C_{n}: \phi\left(z, u_{n}\right) \leq \phi\left(z, z_{n}\right) \leq \phi\left(z, x_{n}\right)+\theta_{n}\right\}, \\
x_{n+1}=\Pi_{C_{n+1}} x_{0}, \quad \forall n \geq 0,
\end{array}\right.
$$

where $J$ is the duality mapping on $E, \theta_{n}=\sup _{q \in F}\left(k_{n}-\right.$ 1) $\phi\left(q, x_{n}\right),\left\{\alpha_{n}\right\},\left\{\beta_{n}\right\},\left\{\gamma_{n}\right\}$ and $\left\{\delta_{n}\right\}$ are sequences in $[0,1]$, $\left\{r_{j, n}\right\} \subset[d, \infty)$ for some $d>0$ and $\left\{\lambda_{n}\right\} \subset[a, b]$ for some $a, b$ with $0<a<b<c^{2} \alpha / 2$, where $\frac{1}{c}$ is the 2-uniformly convexity constant of $E$. If $\alpha_{n}+\beta_{n}+\gamma_{n}=1$ for all 
$n \geq 0$ and $\liminf _{n \rightarrow \infty} \alpha_{n} \beta_{n}>0, \liminf _{n \rightarrow \infty} \alpha_{n} \gamma_{n}>0$, $\liminf _{n \rightarrow \infty} \beta_{n} \gamma_{n}>0$ and $\liminf _{n \rightarrow \infty} \delta_{n}\left(1-\delta_{n}\right)>0$, then $\left\{x_{n}\right\}$ converges strongly to $p \in F$, where $p=\Pi_{F} x_{0}$.

Corollary 3.4. Let $C$ be a nonempty closed and convex subset of a 2-uniformly convex and uniformly smooth Banach space E. For each $j=1,2, \ldots$, m let $f_{j}$ be a bifunction from $C \times C$ to $\mathbb{R}$ which satisfies conditions (A1)-(A4). Let $A$ be an $\alpha$-inverse-strongly monotone mapping of $C$ into $E^{*}$ satisfying $\|A y\| \leq\|A y-A u\|, \quad \forall y \in C$ and $u \in V I(A, C) \neq \emptyset$. Let $\left\{S_{i}\right\}_{i=1}^{\infty}: C \rightarrow C$ be an infinite family of closed quasi- $\phi$ - nonexpansive mappings such that $F:=\cap_{i=1}^{\infty} F\left(S_{i}\right) \cap\left(\cap_{j=1}^{m} E P\left(f_{j}\right)\right) \cap V I(A, C) \neq \emptyset$. For an initial point $x_{0} \in E$ with $x_{1}=\Pi_{C_{1}} x_{0}$ and $C_{1}=C$, we define the sequence $\left\{x_{n}\right\}$ as follows:

$$
\left\{\begin{array}{l}
v_{n}=\Pi_{C} J^{-1}\left(J x_{n}-\lambda_{n} A x_{n}\right) \\
z_{n}=J^{-1}\left(\alpha_{n, 0} J x_{n}+\sum_{i=1}^{\infty} \alpha_{n, i} J S_{i} v_{n}\right), \\
y_{n}=J^{-1}\left(\beta_{n} J x_{n}+\left(1-\beta_{n}\right) J z_{n}\right), \\
u_{n}=T_{r_{m, n}}^{f_{m}} T_{r_{m-1, n}}^{f_{m-1}} \ldots T_{r_{2, n}}^{f_{2}} T_{r_{1, n}}^{f_{1}} y_{n} \\
C_{n+1}=\left\{z \in C_{n}: \phi\left(z, u_{n}\right) \leq \phi\left(z, z_{n}\right) \leq \phi\left(z, x_{n}\right)\right. \\
x_{n+1}=\Pi_{C_{n+1}} x_{0}, \quad \forall n \geq 0
\end{array}\right.
$$

where $J$ is the duality mapping on $E,\left\{\alpha_{n, i}\right\}$ and $\left\{\beta_{n}\right\}$ are sequences in $[0,1],\left\{r_{j, n}\right\} \subset[d, \infty)$ for some $d>0$ and $\left\{\lambda_{n}\right\} \subset[a, b]$ for some $a, b$ with $0<a<b<c^{2} \alpha / 2$, where $\frac{1}{c}$ is the 2-uniformly convexity constant of $E$. If $\sum_{i=0}^{\infty} \alpha_{n, i}=1$ for all $n \geq 0$, $\liminf _{n \rightarrow \infty}\left(1-\beta_{n}\right)>0$ and $\liminf _{n \rightarrow \infty} \alpha_{n, 0} \alpha_{n, i}>0$ for all $i \geq 1$, then $\left\{x_{n}\right\}$ converges strongly to $p \in F$, where $p=\Pi_{F} x_{0}$.

Proof. Since $\left\{S_{i}\right\}_{i=1}^{\infty}: C \rightarrow C$ is an infinite family of closed quasi- $\phi$-nonexpansive mappings, it is an infinite family of closed and uniformly quasi- $\phi$-asymptotically nonexpansive mappings with sequence $k_{n}=1$. Hence the conditions appearing in Theorem $3.1 F$ is a bounded subset in $C$ and for each $i \geq 1, S_{i}$ is uniformly $L_{i}$-Lipschitz continuous are of no use here. By virtue of the closeness of mapping $S_{i}$ for each $i \geq 1$, it yields that $p \in F\left(S_{i}\right)$ for each $i \geq 1$, that is, $p \in \cap_{i=1}^{\infty} F\left(S_{i}\right)$. Therefore all conditions in Theorem 3.1 are satisfied. The conclusion of Corollary 3.4 is obtained from Theorem 3.1 immediately.

Corollary 3.5. (Zegeye 2010, Theorem 3.2) Let $C$ be a nonempty closed and convex subset of a 2-uniformly convex and uniformly smooth Banach space E. Let $f$ be a bifunction from $C \times C$ to $\mathbb{R}$ satisfying $(A 1)-(A 4)$. Let $A$ be an $\alpha$-inverse-strongly monotone mapping of $C$ into $E^{*}$ satisfying $\|A y\| \leq\|A y-A u\|, \quad \forall y \in C$ and $u \in V I(A, C) \neq$ $\emptyset$. Let $\left\{S_{i}\right\}_{i=1}^{N}: C \rightarrow C$ be a finite family of closed quasi- $\phi$ nonexpansive mappings such that $F:=\cap_{i=1}^{N} F\left(S_{i}\right) \cap E P(f) \cap$
$V I(A, C) \neq \emptyset$. For an initial point $x_{0} \in E$ with $x_{1}=\Pi_{C_{1}} x_{0}$ and $C_{1}=C$, we define the sequence $\left\{x_{n}\right\}$ as follows:

$$
\left\{\begin{array}{l}
z_{n}=\Pi_{C} J^{-1}\left(J x_{n}-\lambda_{n} A x_{n}\right), \\
y_{n}=J^{-1}\left(\alpha_{0} J x_{n}+\sum_{i=1}^{N} \alpha_{i} J S_{i} z_{n}\right), \\
f\left(u_{n}, y\right)+\frac{1}{r_{n}}\left\langle y-u_{n}, J u_{n}-J y_{n}\right\rangle \geq 0, \quad \forall y \in C, \\
C_{n+1}=\left\{z \in C_{n}: \phi\left(z, u_{n}\right) \leq \phi\left(z, y_{n}\right) \leq \phi\left(z, x_{n}\right),\right. \\
x_{n+1}=\Pi_{C_{n+1}} x_{0}, \quad \forall n \geq 0,
\end{array}\right.
$$

where $J$ is the duality mapping on $E,\left\{\alpha_{n, i}\right\}$ is sequence in $[0,1],\left\{r_{n}\right\} \subset[d, \infty)$ for some $d>0$ and $\left\{\lambda_{n}\right\} \subset[a, b]$ for some $a, b$ with $0<a<b<c^{2} \alpha / 2$, where $\frac{1}{c}$ is the 2uniformly convexity constant of $E$. If $\alpha_{i} \in(0,1)$ such that $\sum_{i=0}^{N} \alpha_{i}=1$, then $\left\{x_{n}\right\}$ converges strongly to $p \in F$, where $p=\Pi_{F} x_{0}$.

Corollary 3.6. Let $C$ be a nonempty closed and convex subset of a uniformly convex and uniformly smooth Banach space $E$. Let $f$ be a bifunction from $C \times C$ to $\mathbb{R}$ satisfying (A1)-(A4). Let $\left\{S_{i}\right\}_{i=1}^{\infty}: C \rightarrow C$ be an infinite family of closed and uniformly quasi- $\phi$-asymptotically nonexpansive mappings with a sequence $\left\{k_{n}\right\} \subset[1, \infty)$, $k_{n} \rightarrow 1$ and uniformly $L_{i}$-Lipschitz continuous such that $F:=\cap_{i=1}^{\infty} F\left(S_{i}\right) \cap E P(f)$ is a nonempty and bounded subset in $C$. For an initial point $x_{0} \in E$ with $x_{1}=\Pi_{C_{1}} x_{0}$ and $C_{1}=C$, we define the sequence $\left\{x_{n}\right\}$ as follows:

$$
\left\{\begin{array}{l}
y_{n}=J^{-1}\left(\alpha_{n, 0} J x_{n}+\sum_{i=1}^{\infty} \alpha_{n, i} J S_{i}^{n} x_{n}\right), \\
f\left(u_{n}, y\right)+\frac{1}{r_{n}}\left\langle y-u_{n}, J u_{n}-J y_{n}\right\rangle \geq 0, \quad \forall y \in C, \\
C_{n+1}=\left\{z \in C_{n}: \phi\left(z, u_{n}\right) \leq \phi\left(z, y_{n}\right) \leq \phi\left(z, x_{n}\right)+\theta_{n}\right\} \\
x_{n+1}=\Pi_{C_{n+1}} x_{0}, \quad \forall n \geq 0,
\end{array}\right.
$$

where $J$ is the duality mapping on $E, \theta_{n}=\sup _{q \in F}\left(k_{n}-\right.$ 1) $\phi\left(q, x_{n}\right),\left\{\alpha_{n, i}\right\}$ is sequence in $[0,1],\left\{r_{n}\right\} \subset[a, \infty)$ for some $a>0$. If $\sum_{i=0}^{\infty} \alpha_{n, i}=1$ for all $n \geq 0$ and $\lim \inf _{n \rightarrow \infty} \alpha_{n, 0} \alpha_{n, i}>0$ for all $i \geq 1$, then $\left\{x_{n}\right\}$ converges strongly to $p \in F$, where $p=\Pi_{F} x_{0}$.

\section{Deduced to Hilbert spaces}

If $E=H$, a Hilbert space, then $E$ is 2-uniformly convex (we can choose $c=1$ ) and uniformly smooth real Banach space and closed relatively quasi-nonexpansive map reduces to closed quasi-nonexpansive map. Moreover, $J=I$, identity operator on $H$ and $\Pi_{C}=P_{C}$, projection mapping from $H$ into $C$. Thus, the following corollaries hold.

Theorem 4.1. Let $C$ be a nonempty closed and convex subset of a Hilbert space $H$. For each $j=1,2, \ldots$, m let $f_{j}$ be a bifunction from $C \times C$ to $\mathbb{R}$ which satisfies conditions 
(A1)-(A4). Let $A$ be an $\alpha$-inverse-strongly monotone mapping of $C$ into $H$ satisfying $\|A y\| \leq\|A y-A u\|, \quad \forall y \in C$ and $u \in V I(A, C) \neq \emptyset$. Let $\left\{S_{i}\right\}_{i=1}^{\infty}: C \rightarrow C$ be an infinite family of closed and uniformly quasi- $\phi$-asymptotically nonexpansive mappings with a sequence $\left\{k_{n}\right\} \subset[1, \infty)$, $k_{n} \rightarrow 1$ and uniformly $L_{i}$-Lipschitz continuous such that $F:=\cap_{i=1}^{\infty} F\left(S_{i}\right) \cap\left(\cap_{j=1}^{m} E P\left(f_{j}\right)\right) \cap V I(A, C)$ is a nonempty and bounded subset in $C$. For an initial point $x_{0} \in H$ with $x_{1}=P_{C_{1}} x_{0}$ and $C_{1}=C$, define the sequence $\left\{x_{n}\right\}$ as follows:

$$
\left\{\begin{array}{l}
z_{n}=P_{C}\left(x_{n}-\lambda_{n} A x_{n}\right), \\
y_{n}=\alpha_{n, 0} x_{n}+\sum_{i=1}^{\infty} \alpha_{n, i} S_{i}^{n} z_{n}, \\
u_{n}=T_{r_{m, n}}^{f_{m}} T_{r_{m-1, n}}^{f_{m-1}} \ldots T_{r_{2, n}}^{f_{2}} T_{r_{1, n}}^{f_{1}} y_{n}, \\
C_{n+1}=\left\{z \in C_{n}:\left\|z-u_{n}\right\| \leq\left\|z-y_{n}\right\| \leq\left\|z-x_{n}\right\|+\theta_{n}\right\}, \\
x_{n+1}=P_{C_{n+1}} x_{0}, \quad \forall n \geq 0,
\end{array}\right.
$$

where $\theta_{n}=\sup _{q \in F}\left(k_{n}-1\right)\left\|q-x_{n}\right\|,\left\{\alpha_{n, i}\right\}$ is sequence in $[0,1],\left\{r_{j, n}\right\} \subset[a, \infty)$ for some $a>0$ and $\left\{\lambda_{n}\right\} \subset[a, b]$ for some $a, b$ with $0<a<b<\alpha / 2$. If $\sum_{i=0}^{\infty} \alpha_{n, i}=1$ for all $n \geq 0$ and $\liminf \operatorname{in}_{n \rightarrow \infty} \alpha_{n, 0} \alpha_{n, i}>0$ for all $i \geq 1$, then $\left\{x_{n}\right\}$ converges strongly to $p \in F$, where $p=\Pi_{F} x_{0}$.

Remark 4.2. Theorem 4.1 improve and extend the Corollary 3.7 in Zegeye (2010) in the aspect for the mappings, we extend the mappings from a finite family of closed relatively quasi-nonexpansive mappings to more general an infinite family of closed and uniformly quasi- $\phi$ asymptotically nonexpansive mappings.

\section{Zero points of an inverse-strongly monotone operator}

Next, we consider the problem of finding a zero point of an inverse-strongly monotone operator of $E$ into $E^{*}$. Assume that $A$ satisfies the conditions:

(C1) $A$ is $\alpha$-inverse-strongly monotone,

(C2) $A^{-1} 0=\{u \in E: A u=0\} \neq \emptyset$.

Theorem 5.1. Let $C$ be a nonempty closed and convex subset of a 2-uniformly convex and uniformly smooth Banach space $E$. For each $j=1,2, \ldots, m$ let $f_{j}$ be a bifunction from $C \times C$ to $\mathbb{R}$ which satisfies conditions (A1)-(A4). Let $A$ be an operator of $E$ into $E^{*}$ satisfying (C1) and (C2). Let $\left\{S_{i}\right\}_{i=1}^{\infty}: C \rightarrow C$ be an infinite family of closed uniformly $L_{i}$-Lipschitz continuous and uniformly quasi$\phi$-asymptotically nonexpansive mappings with a sequence $\left\{k_{n}\right\} \subset[1, \infty), k_{n} \rightarrow 1$ such that

$$
F:=\cap_{i=1}^{\infty} F\left(S_{i}\right) \cap\left(\cap_{j=1}^{m} E P\left(f_{j}\right)\right) \cap A^{-1} 0
$$

is a nonempty and bounded subset in C. For an initial point $x_{0} \in E$ with $x_{1}=\Pi_{C_{1}} x_{0}$ and $C_{1}=C$, define the sequence $\left\{x_{n}\right\}$ as follows:

$$
\left\{\begin{array}{l}
z_{n}=J^{-1}\left(\alpha_{n, 0} J x_{n}+\sum_{i=1}^{\infty} \alpha_{n, i} J S_{i}^{n} v_{n}\right), \\
y_{n}=J^{-1}\left(\beta_{n} J x_{n}+\left(1-\beta_{n}\right) J z_{n}\right), \\
u_{n}=T_{r_{m, n}}^{f_{m}} T_{r_{m-1, n}}^{f_{m-1}} \ldots T_{r_{2, n}}^{f_{2}} T_{r_{1, n}}^{f_{1}} y_{n}, \\
C_{n+1}=\left\{z \in C_{n}: \phi\left(z, u_{n}\right) \leq \phi\left(z, z_{n}\right) \leq \phi\left(z, x_{n}\right)+\theta_{n}\right\}, \\
x_{n+1}=\Pi_{C_{n+1}} x_{0}, \quad \forall n \geq 0,
\end{array}\right.
$$

where $J$ is the duality mapping on $E, \theta_{n}=\sup _{q \in F}\left(k_{n}-\right.$ 1) $\phi\left(q, x_{n}\right)$, for each $i \geq 0,\left\{\alpha_{n, i}\right\}$ and $\left\{\beta_{n}\right\}$ are sequences in $[0,1],\left\{r_{j, n}\right\} \subset[d, \infty)$ for some $d>0$ and $\left\{\lambda_{n}\right\} \subset[a, b]$ for some $a, b$ with $0<a<b<c^{2} \alpha / 2$, where $\frac{1}{c}$ is the 2uniformly convexity constant of $E$. If $\sum_{i=0}^{\infty} \alpha_{n, i}=1$ for all $n \geq 0, \liminf _{n \rightarrow \infty}\left(1-\beta_{n}\right)>0$ and $\liminf _{n \rightarrow \infty} \alpha_{n, 0} \alpha_{n, i}>$ 0 for all $i \geq 1$, then $\left\{x_{n}\right\}$ converges strongly to $p \in F$, where $p=\Pi_{F} x_{0}$.

Proof. Setting $C=E$ in Corollary 3.4, we also get $\Pi_{E}=I$. We also have $V I(A, C)=V I(A, E)=\{x \in E: A x=0\} \neq$ $\emptyset$ and then the condition $\|A y\| \leq\|A y-A u\|$ holds for all $y \in E$ and $u \in A^{-1} 0$. So, we obtain the result.

\section{Complementarity problems}

Let $K$ be a nonempty, closed convex cone in $E$. We define the polar $K^{*}$ of $K$ as follows:

$$
K^{*}=\left\{y^{*} \in E^{*}:\left\langle x, y^{*}\right\rangle \geq 0, \forall x \in K\right\} .
$$

If $A: K \rightarrow E^{*}$ is an operator, then an element $u \in K$ is called a solution of the complementarity problem (Takahashi 2000) if

$$
A u \in K^{*} \text {, and }\langle u, A u\rangle=0 \text {. }
$$

The set of solutions of the complementarity problem is denoted by $C P(A, K)$.

Theorem 6.1. Let $K$ be a nonempty closed and convex subset of a 2-uniformly convex and uniformly smooth Banach space E. For each $j=1,2, \ldots$, m let $f_{j}$ be a bifunction from $C \times C$ to $\mathbb{R}$ which satisfies conditions (A1)-(A4). Let $A$ be an $\alpha$-inverse-strongly monotone mapping of $K$ into $E^{*}$ satisfying $\|A y\| \leq\|A y-A u\|, \quad \forall y \in K$ and $u \in C P(A, K) \neq$ $\emptyset$. Let $\left\{S_{i}\right\}_{i=1}^{\infty}: K \rightarrow K$ be an infinite family of closed uniformly $L_{i}$-Lipschitz continuous and uniformly quasi$\phi$-asymptotically nonexpansive mappings with a sequence $\left\{k_{n}\right\} \subset[1, \infty), k_{n} \rightarrow 1$ such that $F:=\cap_{i=1}^{\infty} F\left(S_{i}\right) \cap$ $\left(\cap_{j=1}^{m} E P\left(f_{j}\right)\right) \cap C P(A, K)$ is a nonempty and bounded sub- 
set in K. For an initial point $x_{0} \in E$ with $x_{1}=\Pi_{K_{1}} x_{0}$ and $K_{1}=K$, we define the sequence $\left\{x_{n}\right\}$ as follows:

$$
\left\{\begin{array}{l}
v_{n}=\Pi_{K} J^{-1}\left(J x_{n}-\lambda_{n} A x_{n}\right), \\
z_{n}=J^{-1}\left(\alpha_{n, 0} J x_{n}+\sum_{i=1}^{\infty} \alpha_{n, i} J S_{i}^{n} v_{n}\right), \\
y_{n}=J^{-1}\left(\beta_{n} J x_{n}+\left(1-\beta_{n}\right) J z_{n}\right), \\
u_{n}=T_{r_{m, n}}^{f_{m}} T_{r_{m-1, n}}^{f_{m-1}} \ldots T_{r_{2, n}}^{f_{2}} T_{r_{1, n}}^{f_{1}} y_{n}, \\
K_{n+1}=\left\{z \in K_{n}: \phi\left(z, u_{n}\right) \leq \phi\left(z, z_{n}\right) \leq \phi\left(z, x_{n}\right)+\theta_{n}\right\} \\
x_{n+1}=\Pi_{K_{n+1}} x_{0}, \quad \forall n \geq 0,
\end{array}\right.
$$

where $J$ is the duality mapping on $E, \theta_{n}=\sup _{q \in F}\left(k_{n}-\right.$ 1) $\phi\left(q, x_{n}\right)$, for each $i \geq 0,\left\{\alpha_{n, i}\right\}$ and $\left\{\beta_{n}\right\}$ are sequences in $[0,1],\left\{r_{j, n}\right\} \subset[d, \infty)$ for some $d>0$ and $\left\{\lambda_{n}\right\} \subset[a, b]$ for some $a, b$ with $0<a<b<c^{2} \alpha / 2$, where $\frac{1}{c}$ is the 2uniformly convexity constant of $E$. If $\sum_{i=0}^{\infty} \alpha_{n, i}=1$ for all $n \geq 0, \liminf _{n \rightarrow \infty}\left(1-\beta_{n}\right)>0$ and $\liminf _{n \rightarrow \infty} \alpha_{n, 0} \alpha_{n, i}>$ 0 for all $i \geq 1$, then $\left\{x_{n}\right\}$ converges strongly to $p \in F$, where $p=\Pi_{F} x_{0}$.

Proof. As in the proof of Takahashi in (Takahashi 2000, Lemma 7.11), we get that $V I(A, K)=C P(A, K)$. So, we obtain the result.

\section{Competing interests}

The authors declare that they have no competing interests.

\section{Acknowledgements}

I would like to thank the Office of the Higher Education Commission, Thailand for supporting by grant fund under the program Strategic Scholarships for Frontier Research Network for the Join Ph.D. Program Thai Doctoral degree for this research. Furthermore, this research was partially supported by The National Research Council of Thailand (NRCT 2555) and the Faculty of Science, King Mongkut's University of Technology Thonburi (KMUTT). Finally, the authors are grateful for the reviewers for the careful reading of the paper and for the suggestions which improved the quality of this work.

\section{Authors' contributions}

SS and PK conceived the idea, designed the research and wrote the article; SS conducted the research. Both authors have read and approved the final manuscript.

Received: 6 February 2012 Accepted: 10 May 2012

Published: 13 July 2012

\section{References}

Alber YI (1996) Metric and generalized projection operators in Banach spaces: properties and applications. In: Kartsatos AG (ed). Theory and Applications of Nonlinear Operators of Accretive and Monotone Type, 15-50. Marcel Dekker, New York

Alber Yl, Reich S (1994) An iterative method for solving a class of nonlinear operator equations in Banach spaces. Panamer Math J 4: 39-54

Ball K, Carlen EA, Lieb EH (1994) Sharp uniform convexity and smoothness inequalities for trace norm. Invent Math 26: 137-150

Beauzamy B (1985) Introduction to Banach spaces and their Geometry. 2nd edn. Noth Holland, Amsterdam

Blum E, Oettli W (1994) From optimization and variational inequalities to equilibrium problems. Math Student 63: 123-145

Butnariu D, Reich S, Zaslavski AJ (2001) Asymptotic behavior of relatively nonexpansive operators in Banach spaces. J Appl Anal 7: 151-174

Butnariu D, Reich S, Zaslavski AJ (2003) Weak convergence of orbits of nonlinear operators in reflexive Banach spaces. Numer Funct Anal Optim 24: 489-508
Censor Y, Reich S (1996) Iterations of paracontractions and firmly nonexpansive operators with applications to feasibility and optimization. Optimization 37: 323-339

Chang SS, Kim JK, Wang XR (2010) Modified block iterative algorithm for solving convex feasibility problems in banach spaces. J Inequalities App 2010: 14. Article ID 869684

Cholamjiak P (2009) A hybrid iterative scheme for equilibrium problems, variational inequality problems and fixed point problems in Banach spaces. Fixed point theory and App 2009: 19. Article ID 312454

Cholamjiak W, Suantai S (2010) Convergence analysis for a system of equilibrium problems and a countable family of relatively quasi-nonexpansive mappings in Banach spaces. Abstract Appl Anal 2010: 17. Article ID 141376

Cioranescu I (1990) Geometry of Banach spaces. Kluwer, Dordrecht

Combettes PL, Hirstoaga SA (2005) Equilibrium programming in Hilbert spaces. J Nonlinear Convex Anal 6: 117-136

liduka H, Takahashi W (2008) Weak convergence of a projection algorithm for variational inequalities in a Banach space. J Math Anal Appl 339: 668-679

Jaiboon C, Kumam P (2010) A general iterative method for solving equilibrium problems, variational inequality problems and fixed point problems of an infinite family of nonexpansive mappings. J Appl Math Comput 34(1-2): 407-439

Katchang P, Kumam P (2010) A new iterative algorithm of solution for equilibrium problems, variational inequalities and fixed point problems in a Hilbert space. J Appl Math Comput 32: 19-38

Kamimura S, Takahashi W (2002) Strong convergence of a proximal-type algorithm in a Banach space. SIAM J Optim 13: 938-945

Kohsaka F, Takahashi W (2007) "Block iterative methods for a finite family of relatively nonexpansive mappings in Banach spaces." Fixed Point Theory and App 2007: 18. Article ID 21972

Kohsaka, F, Takahashi W (2008) Existence and approximation of fixed points of firmly nonexpansive-type mappings in Banach spaced. SIAM J Optimization 19(2): 824-835

Kikkawa M, Takahashi W (2004) "Approximating fixed points of nonexpansive mappings by the block iterative method in Banach spaces". Int J Comput and Numer Anal App 5(1): 59-66

Kumam P (2009) A new hybrid iterative method for solution of equilibrium problems and fixed point problems for an inverse strongly monotone operator and a nonexpansive mapping. J Appl Math Comput 29: 263-280

Matsushita S, Takahashi W (2004) Weak and strong convergence theorems for relatively nonexpansive mappings in Banach spaces. Fixed Point Theory and Appl 2004: 37-47

Matsushita, S, Takahashi W (2005) A strong convergence theorem for relatively nonexpansive mappings in a Banach space. J Approx Theory 134: 257-266

Moudafi A (2003) Second-order differential proximal methods for equilibrium problems. J Inequal Pure Appl Math 4(art.18). Paper No. 18

Nilsrakoo W, Saejung S (2008) Strong convergence to common fixed points of countable relatively quasi-nonexpansive mappings. Fixed Point Theory and Appl 2008: 19. Article ID 312454

Plubtieng S, Ungchittrakool K (2008) Hybrid iterative methods for convex feasibility problems and fixed point problems of relatively nonexpansive mappings in Banach spaces. Fixed Point Theory and App 2008: 19. Article ID 583082

Qin X, Cho SY, Kang SM (2009a) On hybrid projection methods for asymptotically quasi- $\phi$-nonexpansive mappings. Appl Mathematics Comput 215: 3874-3883

Qin, X, Cho SY, Kang SM (2009b) Strong convergence of shrinking projection methods for quasi- $\phi$-nonexpansive mappings and equilibrium problems. $J$ Comput Appl Math 234: 750-760

Qin X, Cho YJ, Kang SM (2009c) Convergence theorems of common elements for equilibrium problems and fixed point problems in Banach spaces. J Comput Appl Math 225: 20-30

Reich S (1996) A weak convergence theorem for the alternating method with Bergman distance. In: Kartsatos AG (ed). Theory and Applications of Nonlinear Operators of Accretive and Monotone Type, 313-318. Marcel Dekker, New York

Rockafellar RT (1970) On the maximality of sums of nonlinear monotone operators. Trans Amer Math Soc 149: 75-88 
Saewan S, Kumam P (2010a) Modified hybrid block iterative algorithm for convex feasibility problems and generalized equilibrium problems for uniformly quasi- $\phi$-asymptotically nonexpansive mappings. Abstract and Appl Anal 2010: 22. Article ID 357120

Saewan, S, Kumam P (2010b) A hybrid iterative scheme for a maximal monotone operator and two countable families of relatively quasinonexpansive mappings for generalized mixed equilibrium and variational inequality problems. Abstract and Appl Anal 2010: 31. Article ID 123027

Saewan S, Kumam P (2011a) The shrinking projection method for solving generalized equilibrium problem and common fixed points for asymptotically quasi- $\phi$-nonexpansive mappings. Fixed Point Theory and App 2011: 9

Saewan S, Kumam, P (2011b) Strong convergence theorems for countable families of uniformly quasi- $\phi$-asymptotically nonexpansive mappings and a system of generalized mixed equilibrium problems. Abstract and Appl Anal 2011: 27. Article ID 701675

Saewan S, Kumam P (2011c) A modified hybrid projection method for solving generalized mixed equilibrium problems and fixed point problems in Banach spaces. Comput Mathematics with App 62: 1723-1735

Saewan S, Kumam P (2011d) A new modified block iterative algorithm for uniformly quasi- $\phi$-asymptotically nonexpansive mappings and a system of generalized mixed equilibrium problems. Fixed Point Theory and App 2011: 35

Saewan S, Kumam P (2011e) Convergence theorems for mixed equilibrium problems, variational inequality problem and uniformly quasi- $\phi$-asymptotically nonexpansive mappings. Appl Mathematics Comput 218: 3522-3538

Saewan, S, Kumam P (2011f) Convergence Theorems for uniformly quasi- $\phi$-asymptotically nonexpansive mappings, generalized equilibrium problems and variational inequalities. J Inequalities App 2011: 96

Saewan S, Kumam P (2011g) Modified Mann iterative scheme by generalized f-projection for a countable family of relatively quasi-nonexpansive mappings and a system of generalized mixed equilibrium problems. Fixed Point Theory and App 2011: 104

Saewan, S, Kumam P (2012a) A strong convergence theorem concerning a hybrid projection method for finding common fixed points of a countable family of relatively quasi-nonexpansive mappings. J Nonlinear and Convex Anal 13(2): 313-330

Saewan S, Kumam P (2012b) A generalized $f$-projection method for countable families of weak relatively nonexpansive mappings and the system of generalized ky fan inequalities. J Global Optimization. doi:10.1007/s10898-012-9922-3

Saewan S, Kumam P, Wattanawitoon K (2010) Convergence theorem based on a new hybrid projection method for finding a common solution of generalized equilibrium and variational inequality problems in Banach spaces. Abstract and Appl Anal 2010: 26. Article ID 734126

Su Y, Wang D, Shang M (2008) Strong convergence of monotone hybrid algorithm for hemi-relatively nonexpansive mappings. Fixed Point Theory and Appl 2008: 8. Article ID 284613

Takahashi W (2000) Nonlinear Functional Analysis. Yokohama-Publishers, Yokohama

Takahashi Y, Hashimoto K, Kato M (2002) On sharp uniform convexity, smoothness, and strong type, cotype inequalities. J Nonlinear Convex Anal 3: $267-281$

Takahashi W, Zembayashi K (2008) Strong convergence theorem by a new hybrid method for equilibrium problems and relatively nonexpansive mappings. Fixed Point Theory and Appl 2008: 11. Article ID 528476

Takahashi, W, Zembayashi K (2009) Strong and weak convergence theorems for equilibrium problems and relatively nonexpansive mappings in Banach spaces. Nonlinear Anal 70: 45-57

Wattanawitoon K, Kumam P (2009) A strong convergence theorem by a new hybrid projection algorithm for fixed point problems and equilibrium problems of two relatively quasi-nonexpansive mappings. Nonlinear Anal: Hybrid Syst 3(1): 11-20

Xu HK (1991) Inequalities in Banach spaces with applications. Nonlinear Anal 16: $127-1138$

Zalinescu C (1983) On uniformly convex functions. J Math Anal Appl 95 $344-374$

Zegeye H (2010) A hybrid iteration scheme for equilibrium problems, variational inequality problems and common fixed point problems in Banach spaces. Nonlinear Anal 72: 2136-2146
Zegeye H, Shahzad N (2009) Strong convergence for monotone mappings and relatively weak nonexpansive mappings. Nonlinear Anal 70: 2707-2716

Zegeye H, Ofoedu EU, Shahzad N (2010) Convergence theorems for equilibrium problem, variational inequality problem and countably infinite relatively quasi-nonexpansive mappings. Appl Mathematics Comput 216: 3439-3449

doi:10.1186/2193-1801-1-8

Cite this article as: Saewan and Kumam: The hybrid block iterative algorithm for solving the system of equilibrium problems and variational inequality problems. SpringerPlus 2012 1:8.

\section{Submit your manuscript to a SpringerOpen ${ }^{\circ}$ journal and benefit from:}

- Convenient online submission

- Rigorous peer review

- Immediate publication on acceptance

- Open access: articles freely available online

- High visibility within the field

- Retaining the copyright to your article

Submit your next manuscript at $\boldsymbol{\wedge}$ springeropen.com 